\title{
Deconstructing Demons: The Case of Geoffrey
}

\section{JAN MOHLMAN ${ }^{\mathrm{a}, \mathrm{b}}$, LINDA A. CEDENO ${ }^{\mathrm{a}}$, REBECCA B. PRICE ${ }^{\mathrm{a}}$, ERIC B. HEKLER ${ }^{a}$, GRACE W. YAN ${ }^{a}$, \& DANIEL B. FISHMAN ${ }^{a}$}

${ }^{a}$ Rutgers - The State University of New Jersey, Piscataway, NJ, USA

${ }^{\mathrm{b}}$ Correspondence concerning this article should be addressed to Jan Mohlman, Rutgers University Psychology

Department, 152 Frelinghuysen Road, Piscataway, NJ 08854, USA.

Email: jmohlman@rci.rutgers.edu

\begin{abstract}
Research in late life mental health has not kept pace with the rapidly aging population of the U.S. Older adults (over age 65), more specifically the "baby boomer" cohort, are likely to pose unique challenges to mental health care providers. This report describes the case of Geoffrey, a 66-yearold African American male who presented with a complex range of psychiatric conditions (e.g., major depressive disorder, social anxiety disorder, and a history of polysubstance dependence), and challenging life circumstances (e.g., limited financial and social resources, and poorly controlled medical illness). Because Geoffrey also evidenced impairment in several cognitive domains (attention, memory, executive functions), a combined intervention of executive skills training (Sohlberg, Johnson, Paule, Raskin, \& Mateer, 2001) and cognitive behavior therapy (CBT) was selected. Furthermore, because time for conducting therapy was limited (fourteen, 90-minute sessions over a ten-week period), a "transdiagnostic" approach was taken to maximize efficiency. Results suggest the utility of augmented, transdiagnostic therapies to achieve optimal response with older clients. Although Geoffrey's intervention progressed well, an event occurring late in treatment changed the course of therapy and led to an unexpected outcome. Several noteworthy aspects of the intervention, including the relevance of Geoffrey's case to the current aging trend in the U.S., the use of a combined transdiagnostic intervention, and aspects of the therapy process are discussed throughout.
\end{abstract}

Keywords: aging; comorbidity; transdiagnostic approach; cognitive behavior therapy (CBT); executive skills training; baby boomers; African American

\section{CASE CONTEXT AND METHOD}

\section{Background About the Mental Health Treatment of Older Adults}

The U.S. population is undergoing a major demographic shift. It is estimated that by the year 2030, the number of older adults (over the age of 65) will have tripled as compared to the year 2000 (Kinsella \& Velkoff, 2001). Along with the growing older adult population comes a corresponding expectation of increased rates of psychiatric disorders such as anxiety and depression (Blazer, 2003; Kessler, 2005). Unfortunately, research in late-life mental health has not kept pace with this trend, and we face a burgeoning public health problem as the U.S. 
population ages. We are not well prepared for the challenge of providing services to this unique demographic subgroup (Blow \& Oslin, 2003; Laidlaw, Thompson, Dick-Siskin, \& GallagherThompson, 2003). Recently, researchers have begun to stress the importance of prioritizing research to address the mental health needs of this rapidly growing age group (Reynolds \& Gatz, 2003).

The individuals who comprise the upcoming cohort of older adults (affectionately called the "baby boomers") were born after World War II and raised in prosperous times. They experienced first-hand the civil rights movement of the 1960s and 70s, followed by the economically and politically tumultuous end of the $20^{\text {th }}$ and start of the $21^{\text {st }}$ centuries. They are the first cohort whose lives have been influenced by mass media and lifelong access to health care services, with a focus on longevity and quality of life (Storandt, 1983). As such, they are expected to be more knowledgeable and savvy about mental health than any previous cohort of adults over the age of 65 . This increased knowledge regarding mental health is also expected to make them discriminating and assertive consumers of available services.

On the other hand, we can also speculate that the baby boomers may be the first cohort of elderly to experience the many challenges of nontraditional adult life. For instance, they might be the first group to have lived with advanced stages of disease (e.g., some cancers, acquired immunodeficiency syndrome) due to recent progress in medical interventions. With increased longevity, baby boomers are more likely than previous older adult cohorts to be impacted by cognitive and emotional disorders. They may also be more likely than previous cohorts to have personal experience with social problems such as substance abuse and addictions, divorce and family discord, domestic violence, and terrorism. All of these factors could have a negative impact on overall functioning, and indeed, a substantially growing number of adults in the baby boomer generation report mental health problems.

Older adults are more likely to consult a primary care physician than a mental health specialist, which can decrease the chances that emotional problems will be accurately diagnosed. Additionally, the diagnosis of emotional disorders is complicated by comorbid, age-related medical problems. Psychiatric symptoms can easily be mistaken as physical symptoms of aging or preexisting disease (e.g., vascular disease [Alexopoulos et al., 1997]). In some cases, certain disorders such as depression might be considered to be a "normal" experience for older adults because of aging (Gallo, Ryan, \& Ford, 1999; Laidlaw et al., 2003). Life stressors (such as caregiving for one's parent and child at the same time) also decrease the likelihood of baby boomers finding the time to engage in mental-health, help-seeking behaviors (Lehmann, 2003). As such, it is widely believed that reported prevalence rates of psychopathology among older adults are underestimations of the true prevalence of various mental disorders.

Even with the aforementioned factors that compromise the accurate detection of psychopathology in the older population, epidemiological studies have found steadily increasing rates of disorders among older adults. It is anticipated that the number of adults over the age of 65 with psychiatric disorders will rise from 4 million in 1970 to 15 million in 2030, with the sudden increase in reported disorders beginning with the baby boomer population (Jeste et al., 1999). A population study of more than 1.4 million residents in Canada found that 
approximately $23.8 \%$ of older adults used mental-health-related medication in 2002, a significant $12 \%$ increase from reported rates in 1993. There was also a significant, $60 \%$ increase in psychiatric drug prescriptions dispensed per older adult resident, and mental health drug prescription costs rose from $\$ 32.00$ per older adult in 1993 to $\$ 99.00$ per older adult resident in 2002. Approximately 25\% of all older adults living in Ontario used some form of mental health medication by the end of 2002, with antidepressants quickly becoming the most commonly prescribed type of medication (Mamdani, Rapoport, Shulman, Hermann, \& Rochon, 2005).

The Epidemiologic Catchment Area (ECA) study conducted in the 1980s found that about $13 \%$ of older adults meet criteria for psychiatric disorders other than dementia (Robins \& Regier, 1991). More recent data is concordant with these earlier findings. According to data from the 2000 U.S. Census, approximately 11\% of adults over the age of 65 report a mental or emotional disability that impairs daily functioning (Gist \& Hetzel, 2004). Taken together, anxiety (Flint, 1994) and depressive disorders (Conwell, 2001) comprise the most frequently occurring psychiatric conditions in adults over the age of 65. In light of the difficulties in accurately diagnosing mental disorders in older adults (e.g., misdiagnosing of psychiatric symptoms as physical symptoms, underreporting of symptoms, and the impact of stigma), it is hypothesized that actual prevalence rates may be $25 \%$ higher than what is actually reported (Jeste et al., 1999). In addition, baby boomers are expected to be at higher risk for specific disorders (such as depression, anxiety disorders, and substance abuse disorders) than previous cohorts of older adults (Klerman \& Weissman, 1989; White, Aidala, \& Zablocki, 1998). Another issue of particular concern for baby boomers is suicide risk. In 1994, baby boomers represented 1 out of every 3 successful suicides (McIntosh, 1994). With the prevalence of underdiagnosed mental disorders and other age-related stressors in their lives, more research into strategies for improving the emotional and mental well-being of older adults is needed.

Interventions for anxiety and depression have been extensively studied in middle-aged adults. Results from these trials can inform treatment of the elderly until research with older adults indicates the superiority of one strategy over the others. One of the most effective interventions for these conditions, cognitive behavior therapy (CBT), might be particularly appealing to the upcoming cohort of older adults (e.g., Laidlaw et al., 2003). CBT is collaborative, interactive, relatively brief, self-focused, and solution-oriented, attributes which seem to be consistent with baby boomer values (Morris \& Morris, 1991). Recent clinical trials of CBT indicate variable outcomes, mostly ranging from fair to good rates of response to CBT in samples of depressed and anxious older adults (Laidlaw et al., 2003; Mitte, 2005; Mohlman, 2004).

The case of Geoffrey was chosen for this report because he exemplifies many of the problems the baby boomer cohort are likely to face as contemporary medicine extends the lifespan, including emotional and behavioral disorders; chronic medical conditions; cognitive deficit; histories of substance abuse; lives that have included some intensely, emotionally difficult circumstances; and challenging circumstances in present life situations (e.g., limited financial and social resources). 


\section{Methods for Documenting the Case of Geoffrey}

A number of steps were taken to document Geoffrey’s case. He signed a consent form allowing the therapist to collect data and publish results of the intervention. All therapy sessions were audiotaped. Self-report questionnaire and diagnostic interview data were collected at preand post-treatment, and at six-month follow up. Neuropsychological test data were collected at pre- and post-treatment. Written assignments, mood rating data, and process measures were collected throughout treatment. The first author acted as the pretreatment assessor and therapist, and a graduate student at a nearby university in an urban region in the Northeast U.S. conducted the post-treatment and follow-up assessments. Because Geoffrey had no automobile, therapy was conducted in a semi-private room at a senior center near his home or at the therapist's university if the weather was nice enough for him to walk the mile to the therapist's office. Data were kept confidential through the use of a numerical code assigned to all records, including therapy notes, self-report questionnaires, and neuropsychological test results.

\section{The Case Write-up as a Joint Research and Training Project}

This case write-up served the joint purpose of both research and clinical training for graduate students in clinical psychology who were enrolled in the first author's practicum. A primary goal of the practicum is to teach methods for conducting clinical trials of cognitive behavior therapy (CBT) for anxiety and mood disorders, with particular regards to older adults. During group supervision meetings, case-study methodology was discussed as an avenue for examining change processes in intervention research. The present case of Geoffrey was chosen for a systematic case study based on its rich clinical presentation and potential for didactic training in several domains (e.g., CBT, diversity, cognitive training, and health psychology). The first author presented the case, and then assigned sections for each practicum student to write (e.g., theoretical background and session summaries). The sections were aggregated and the complete manuscript was distributed to the group and the last author for critical evaluation and additional editing.

\section{THE CLIENT}

Geoffrey is a divorced, African American male born in the mid 1930s. At the time he presented for treatment, he was 66-years-old, unemployed, and living alone in a small, oneroom apartment in a city in the Northeastern U.S.

Geoffrey was recruited from a senior center, where he volunteered in the kitchen and dining room several days per week. When he didn't meet criteria for a research study being conducted by the first author (J.M.), he was offered pro bono psychotherapy. Interestingly, even before our meeting, Geoffrey had been looking for a clinic that offered CBT. After reading a newspaper article about CBT for depression, Geoffrey realized that the details of the case described in the article bore a striking similarity to his own circumstances. He believed that the "common sense approach" of the therapy would be helpful to him. Because of his fixed income and limited resources, it was unlikely that Geoffrey could have afforded treatment from a 
practitioner in the community, and his mental health care services were limited to those offered by a local Veterans’ Hospital, where CBT was not offered.

At intake, Geoffrey's presenting goals were to overcome anxiety and depression; "fill his life back up;" increase his levels of social, intellectual, and occupational functioning; and "feel better about himself.”

\section{GUIDING CONCEPTION, WITH RESEARCH AND CLINICAL EXPERIENCE SUPPORT}

\section{Cognitive-Behavior Therapy (CBT) for Emotional and Behavioral Problems}

The theoretical model employed in this case is cognitive-behavior therapy (CBT). This approach focuses on the individualized adaptation of manualized packages of specific interventions targeted towards specific, presenting problems (e.g., Barlow, 2007). As an approach to therapy, CBT can be generally characterized as collaborative, interactive, relatively brief, self-focused, and solution-oriented (Morris \& Morris, 1991). The sources of the interventions include both behavioral and cognitive components. The behavioral components are based on psychological learning principles, such as classical and operant conditioning and modeling, leading to such procedures as exposure and response prevention for compulsions and phobias; behavioral activation for depression; and contingency management for substance disorders.

The cognitive components are generally based on cognitive psychology. This approach emphasizes that the response of an individual to a situation is heavily influenced by how the individual interprets and construes his environment rather than just upon the objective nature of the situation itself. Cognitive therapists have developed a variety of procedures for exploring and confronting a client's dysfunctional ways of thinking about situations that are difficult for them. An important tenet of this model, and one quite important for clients like Geoffrey, is that the way a patient thinks about a situation contributes to how he or she feels about it, and thus that one way to address debilitating depression and anxiety is to examine and challenge the situationally stimulated thoughts that lead to these feelings and to find alternative ways of thinking that are more functional - a process sometimes known as "cognitive restructuring."

\section{A “Transdiagnostic” Approach}

Geoffrey's diagnostic evaluation revealed a complex assemblage of discrete diagnoses, including major depressive disorder, severe claustrophobia, and social anxiety disorder, as well as subsyndromal features of posttraumatic stress disorder and a past history of polysubstance dependence. This multifaceted clinical presentation necessitated thoughtful selection of primary and secondary targets of intervention. In earlier years of CBT development, there was a preference for serial treatment for polysyndromal patients like Geoffrey, with depressive symptomatology being advocated as the first target of intervention. Once depressed mood was alleviated, it was believed, the behavioral work of anxiety treatment (e.g., exposure exercises) would be facilitated. 
More recently, a growing empirical literature has focused on the shared, transdiagnostic features that typify mood and anxiety disorders, calling into question the utility of a serial treatment approach (e.g., Brown \& Barlow, 2002). An influential model that seeks to organize these overlapping symptoms is the tripartite model of depression and anxiety (Clark \& Watson, 1991). The model was developed through factor analysis of mood and anxiety symptom questionnaires, which revealed three discrete symptom factors: negative affect, or the tendency to experience distressful negative mood states such as fear, sadness, anger, and guilt; positive affect, or the tendency to experience positive mood states such as joy, energy, enthusiasm, and interest; and physiological hyperarousal. While negative affect is uniformly high in mood and anxiety disorders alike, positive affect is more closely (negatively) related to depressive symptomatology, while arousal symptoms are relatively specific to the fear disorders (for a review, see Mineka, Watson, \& Clark, 1998). This three-factor solution to mood and anxiety symptoms has been replicated in a wide range of clinical and non-clinical samples, including older adults seeking psychiatric outpatient treatment (Cook, Orvaschel, Hersen, \& Joiner, 2004).

The accumulation of data in support of the tripartite model has fueled a call for revisions to the diagnostic system that guides clinical practice. Although the topic remains controversial, some have argued in favor of supplementing (e.g., Brown \& Barlow, 2005) or replacing (Clark, 2005) the current categorical system with a dimensional approach to patient classification, in which core factors shared across multiple disorders, including negative affectivity, positive affectivity, and fear/arousal symptoms, would be rated along a continuum of severity. Individual patients could then be treated based on their presentation along these core dimensions, rather than on the basis of their membership in discrete psychopathological categories.

In clinical practice, this shift in nosological theory implies that a treatment approach targeting discrete disorders with specific protocols may be less efficient than an approach that directly targets a common core pathology, such as negative affectivity. Unfortunately, this prediction has yet to be systematically tested in treatment outcome research. Some evidence exists to suggest that a serial or strictly diagnosis-driven approach may be suboptimal for individuals with comorbid diagnoses, particularly in the longer term. For example, Brown, Antony, and Barlow (1995) found that in patients receiving CBT for panic disorder, comorbidity rates that declined over the course of treatment (from $40 \%$ to $17 \%$ at post-treatment assessment) returned to pre-treatment levels (30\%) at 2-year follow up, suggesting the possibility that a predispositional vulnerability factor was not effectively ameliorated by the standard diagnosisdriven approach.

To date, only one study has tested the efficacy of a transdiagnostic treatment approach for patients with comorbid anxiety and depressive disorders (Norton, Hayes, \& Hope, 2004). A heterogeneous sample of 23 patients with a range of principal anxiety diagnoses were randomized to a waitlist condition or to a 12-week CBT protocol that included psychoeducation, exposure and response prevention (in vivo, role-played, imaginal, or interoceptive exposures, as appropriate), and relapse prevention. In comparison to the wait-list group, patients receiving transdiagnostic CBT improved on both primary outcome measures of anxiety severity as well as measures of depressive symptom severity. The study was inadequately powered to test the effect of the protocol on comorbid depressive diagnoses, as only 8 participants met criteria for a 
comorbid mood disorder; however, in three of four treated patients with comorbid depressive diagnoses at baseline, the comorbid depressive disorder had remitted upon completion of CBT.

An additional, multisite randomized control trial is currently underway to examine the effect of transdiagnostic CBT on mixed anxiety diagnoses. Preliminary results from this study (Laposa, Janeck, Erickson, \& Tallman, 2003) as well as several uncontrolled pre-post evaluations of similar transdiagnostic protocols (Barlow et al., 2003; Erickson, 2003; White Lumpkin, Silverman, Weems, Markham, \& Kurtines, 2002) have supported the emerging theoretical view that diagnostic categories need not dictate the selection of CBT protocols.

Given the dearth of empirical data available to guide the selection of a treatment plan for Geoffrey's complex clinical presentation, contemporary transdiagnostic conceptualizations of mood and anxiety syndromes informed our selection of a parallel, rather than a serial, treatment approach. Overlapping mechanisms maintaining a range of negative affective states (e.g., social withdrawal and avoidance, negative views of self, cognitive distortions) were chosen as the initial targets of treatment, rather than any single diagnostic symptom cluster.

Additionally, it was known at the onset of treatment that the therapist would soon relocate to another city, therefore Geoffrey would attend therapy sessions for ten to twelve weeks, depending on the details of scheduling. As such, the guiding principle of the intervention was efficiency, and thus problems, rather than disorders per se, were targeted. Whenever possible, the therapist first applied techniques that might affect multiple symptoms, or those symptoms that were shared by two or more disorders, followed by more targeted interventions for disorder-specific symptoms.

\section{Cognitive Training for Problems in Attention, Memory, and Executive Functioning}

Pilot work from the first author's lab suggests that sound executive skills (complex cognitive operations governed by the frontal lobes; Norman \& Shallice, 1986) might be necessary for the successful use of CBT (Mohlman, 2005; Mohlman \& Gorman, 2005). For instance, CBT hinges upon the client's ability to engage in focusing, dividing, and shifting attention, self monitoring, metacognition, and perspective taking, all of which involve executive abilities (e.g., Fuster, 1997). In the process of normal aging, there are psychological (Carstensen, Gross, \& Fung, 1997; Willis \& Schaie, 1986), biological (Goldman-Rakic \& Brown, 1981; Hachinski, Potter, \& Merskey, 1987), cultural, and cohort effects (Rabbitt \& Lowe, 2000) that can interfere with executive skills, putting older adults at risk for poorer therapy response relative to the young.

There is also evidence to suggest that the relationship between depression and chronic illness is moderated by executive functioning, e.g., patients with a chronic illness and low executive functioning tend to be more depressed than patients with higher executive functioning (Mast, Yochim, MacNeill, \& Lichtenberg, 2004). In addition, impaired cognitive abilities have been found to independently predict increased risk of mortality among chronic disease patients (Feil, Marmon, \& Unutzer, 2003). As stated earlier, depression, diabetes, and hypertension have all been linked to poor cognitive abilities (Hassing et al., 2004). Taken collectively, this 
evidence supports the need for interventions focused on improving cognitive abilities, which can in turn improve chronic disease management and mood, potentially leading to long-term changes in outcomes such as mortality.

Through repeated practice, executive skills can often be substantially improved (Sohlberg \& Mateer, 2000). Thus, one potentially effective strategy for enhancing CBT and improving mood might be the addition of an executive skills rehabilitation program to the intervention. To date, cognitive training has been successfully used as an adjunctive treatment for psychiatric disorders such as schizophrenia (Bell, Fiszdon, Bryson, \& Wexler, 2004; Bell, Bryson, Greig, Corcoran, \& Wexler, 2001; Fiszdon, Bryson, Wexler, \& Bell, 2003; Lopez-Luengo, \& Vazquez, 2003; Silverstein et al., 2004), major depression (Siegle, Ghinassi, \& Thase, 2007), and substance abuse (Fals-Stewart, 2006).

As noted above, our previous studies indicate that intact executive functions may be necessary in order for older patients to respond to cognitive behavioral therapy (Mohlman \& Gorman, 2005). We recently tested CBT combined with a standardized executive training package, Attention Process Training II (APT II; Sohlberg, Johnson, Paule, Raskin, \& Mateer, 2001) against CBT alone (Mohlman, in press). The pilot sample was comprised of eight adults age 60 to 74, mean age 66.4. All participants met criteria for generalized anxiety disorder. Participants completed a packet of self-report questionnaires and a neuropsychological test battery. Following the assessment, all participants completed an eight-week waiting period meant to serve as a control for the treatment conditions. There were no changes in clinical status of any participant during the waiting period. After a second assessment, each was randomly assigned to 8 ninety-minute weekly sessions of either CBT $(n=4)$ or CBT/APT $(n=4)$. CBT/APT included the same manual and modules as in standard CBT, plus Mental Math Activity, Alternating Alphabet Stimuli, Sentence Stimuli, Sustained Auditory Attention, and Article Scan tasks, which are briefly described below in the Assessment section. Participants practiced these tasks in session for 45 minutes (sessions 1-4), and as homework (sessions 1-8), with the remainder of each session devoted to CBT. Immediately following treatment, participants completed a post-treatment assessment and six-month follow-up period. The CBT/APT group showed a significant improvement in executive skills following the intervention. Twice the number of participants in CBT/APT as compared to CBT met criteria for response, and more for high end-state functioning at post-treatment, and these results held at the six month follow-up assessment, suggesting durability.

Geoffrey's case presented an opportunity to try the cognitive training approach in an older individual with both a complex set of emotional and behavioral problems and documented deficits in executive functioning.

\section{ASSESSMENT OF THE CLIENT'S PRESENTING PROBLEMS, STRENGTHS, AND GOALS}

\section{History}

It is assumed that Geoffrey's report of his history is accurate, although he admitted that his memory for details during periods of heavy drug use (over a period of 5 years, ending 3 years before he started treatment) was patchy and likely to be somewhat less accurate. 
Geoffrey reported a happy childhood with no traumatic events. He grew up in a small semi-rural town with his biological parents and one older brother. His father worked in a steel factory and his mother was a housekeeper. After graduating from high school, Geoffrey attended a local university for two years, majoring in English. He had been an avid reader, and had planned to become an English teacher, but dropped out of college in his sophomore year because the ongoing evaluative stress of being a student made him very anxious. He found oral presentations and working in groups with other students particularly distressing and difficult. He had also been politically active in the 1980's and 1990's, but had stopped attending political events because "people made him nervous."

He left college without a degree and subsequently held a series of administrative jobs, most notably as a mailroom administrator at an army base. In the 1970's Geoffrey went voluntarily to Vietnam to work in an army mail facility. Upon his return, he took an administrative job at a local Veteran's Affairs Hospital (V.A.), which was his most recent place of employment.

Geoffrey's life changed dramatically in the 1980's when his friends from the V.A. introduced him to crack cocaine. He quickly became addicted and over next 10 years, "lost everything” including his job, his wife and family, his house, two cars, and all his "straight-edge friends.” During this period of drug use, he moved from his family's house into a small apartment in a neighboring town. Geoffrey survived by using his credit cards, and accrued over $\$ 75,000.00$ in debt over the next several years.

Also during this phase of his life, he began to have sexual relations with women other than his wife, mostly other drug users. After using crack cocaine with a female friend in her apartment in the mid 1990s, she suffered a heart attack and died while sitting next to him in bed. Because he was intoxicated and could not think clearly about how to handle the situation, Geoffrey left the apartment and walked around the block several times to "get his head on straight." He called the police, who took a full report on her death. He was arrested for being "under the influence of an illegal substance" and mandated for drug treatment. However, he did not undergo criminal charges relative to the death of his girlfriend. Geoffrey was ostracized from his family when they learned of the event, leading to his divorce. He reported the onset of symptoms of PTSD soon after his girlfriend's death, including flashbacks, hypervigilance, mistrust of people, and emotional numbing.

Geoffrey's ex-wife died of pancreatic cancer three years later, at which time they had not resolved any of the issues surrounding his drug use, misuse of the family's resources, or infidelity.

When therapy began, Geoffrey had four estranged adult daughters aged 31, 35, 37, and 40. He had been divorced for 6 years and, as mentioned above, his ex-wife had died of cancer 3 years earlier. He lived off a modest social security pension, and had no phone or car. Geoffrey was in good physical health although he had high blood pressure and had recently been diagnosed with Type II diabetes; and he was not adhering consistently to the self-care regimen recommended by his doctor. He smoked half a pack of cigarettes each day, but didn't drink 
alcohol. He did report a past, 15-year history of alcohol and polysubstance dependence, primarily accounted for by marijuana and crack cocaine.

At the time Geoffrey presented for treatment, he had successfully completed two 28-day inpatient detoxification programs, managed to stop using crack and other substances, and wanted to "build his life back up." He had been clean for 3 years.

\section{Structured Assessment Methods}

The goals of the structured assessment were (a) to evaluate the severity of Geoffrey's symptoms of depression, anxiety, and cognitive impairment; (b) to assess the possible influence of past problems on his current functioning; and (c) to evaluate the contributions made by these symptoms and past problems, by Geoffrey's health conditions, and by his limited financial resources on his overall functioning.

To assess anxiety and depression symptoms, Geoffrey completed a packet of self-report questionnaires comprised of (a) the Beck Depression Inventory (BDI; Beck \& Steer, 1987); (b) the Geriatric Suicidal Ideation Scale (GSIS; Heisel \& Flett, 2001); (c) the Social Anxiety Interaction Scale (SAIS; Mattick \& Clark, 1998); (d) the Beck Anxiety Inventory (BAI; Beck \& Steer, 1990); and (e) the State-Trait Anxiety Inventory (STAI; Spielberger, Gorsuch, Lushene, Vagg, \& Jacobs, 1983).

To assess Geoffrey's cognitive functioning, he was given a battery of cognitive and neuropsychological tests, including (a) the Digit Span and Similarities subscales of the Wechsler Adult Intelligence Scales (Wechsler, 1997); (b) the Verbal Paired Associates subscale of the Wechsler Memory Scales (Wechsler, 1997); (c), the Stroop Test of Color Word Interference (Trenerry Crosson, DeBoe, \& Leber, 1989); and (d) the Controlled Oral Word Association Test (COWAT; Miller, 1984). Scores on these tests appear in Tables 1 and 2.

\section{Present Life Patterns, Symptoms, and Diagnostic Information}

\section{$\underline{\text { Emotional and Behavioral Problems }}$}

Geoffrey completed the Structured Clinical Interview Diagnostic for DSM-IV (SCID [First, Gibbon, Spitzer, \& Williams, 1995]), which was administered by the first author. He acknowledged that he was depressed, and endorsed several symptoms of major depressive disorder: anhedonia for three months, low motivation, lack of energy, feelings of worthlessness and inappropriate guilt, trouble concentrating and making decisions, and thoughts of his own death. Geoffrey had cut out most activities over the past year. Additionally, he reported several cognitive symptoms, such as frequent rumination and regretful thoughts. He also had a short attention span, and expressed a subjective feeling that his "brain was dead" and he felt like "a very old man.” He reported that he spent most of his time watching television, which he believed "prevented loneliness." Geoffrey perceived a worsening of symptoms over the past two months. He also said that his apartment had begun to "make him uncomfortable" for reasons he 
was not able to articulate. Geoffrey viewed himself as a worthless, insecure failure. He felt that the events of his life caused him to always "aim low."

Although Geoffrey seemed friendly and outgoing and was compliant with the interviewer, he said that he often experienced mild to moderate levels of anxiety when interacting with unfamiliar people across a variety of contexts (parties, meetings, interviews, community events). He feared negative evaluation by others and had the distinct feeling that others could "see all the mistakes of his past just by looking at him," a belief that caused him distress and discomfort on a daily basis. As mentioned above in the history section, these symptoms of social anxiety had been present for much of his adult life.

Geoffrey also reported severe claustrophobia which began in young adulthood and grew worse over time. He was unwilling to ride in elevators, even for short distances; felt nervous stepping into closets; disliked small, hot rooms; and was not willing to attempt to put a paper grocery bag over his head for ten seconds, which was a diagnostic exercise created "on the fly" by the interviewer. Geoffrey served in a non-combat position in Vietnam in which he managed a mail center. By his report, he chose to stay six extra weeks in Vietnam to avoid traveling home to the U.S. on a ship that had very small living quarters, a choice that could have increased his chances of being harmed. This choice, and the description of his symptoms, indicated severe levels of avoidance of closed-in places driven by suffocation fears.

In sum, according to the SCID interview, Geoffrey met Diagnostic and Statistical Manual for DSM-IV (APA, 2000) criteria for Major Depressive Disorder (Recurrent), Social Anxiety Disorder (Generalized, Moderate), and Claustrophobia (Severe). He reported impairing symptoms of Posttraumatic Stress Disorder, but did not meet full criteria. He also met criteria for Polysubstance Dependence in Sustained Full Remission. The formal details of his diagnosis, along with later diagnoses he received at post-treatment and at 6-months follow-up, are presented in Table 3.

\section{Cognitive Functioning Problems}

During the structured testing of Geoffrey's cognitive functioning, he demonstrated a very short attention span, often asking to take breaks during the diagnostic interview and neuropsychological testing. The interviewer had to refresh Geoffrey's memory of the instructions of a subset of the tests, and he was easily distracted by extraneous noises outside the testing room, which occasionally caused him to lose attentional set. He also had difficulty speaking or listening while writing.

\section{Strengths}

Geoffrey had prior knowledge of CBT and mental health issues before presenting for treatment, and was enthusiastic about participating in therapy. He was well educated, valued the idea of lifelong learning, and earlier in his life he had been an avid reader. Geoffrey had also been politically active earlier in his life, and did volunteer work in the community, suggesting compassion and an awareness of social issues. 


\section{Goals}

As mentioned above, at the beginning of therapy, Geoffrey's goals were to overcome anxiety and depression, "fill his life back up," increase his levels of social, intellectual, and occupational functioning, and "feel better about himself."

\section{FORMULATION AND TREATMENT PLAN}

\section{Formulation}

\section{$\underline{\text { Factors leading to Anxiety, Substance Abuse, and Depression }}$}

Geoffrey’s history suggests that he had a generally supportive and nurturing family and social environment through high school. However, this was accompanied by an undiagnosed, untreated generalized anxiety disorder, which was particularly in evidence when Geoffrey had to deal with unfamiliar situations and people, especially situations with a significant evaluative component. It appears that his disorder got worse when he left the security of his home in a semi-rural area to live independently and attend a large, cosmopolitan university. Thus, while he had been an avid reader who had been planning to be an English teacher, the evaluative pressures of being a student caused Geoffrey to become anxious enough to leave college and settle for less demanding, relatively low-level administrative positions, which was a blow to his self-image and self-esteem. With diminished self-esteem and an untreated anxiety disorder, Geoffrey was susceptible to substance abuse as a way to self-medicate. It was in this context that he fell into a 15-year history of alcohol and polysubstance dependence.

Another symptom of Geoffrey’s anxiety disorder was his reported severe claustrophobia, which began in young adulthood and grew worse over time. A dramatic example of this was his staying an extra six weeks in Vietnam to avoid traveling home on a ship with very small living quarters, even though this decision increased his chances of being harmed.

Starting in 6 years before the beginning of therapy, Geoffrey experienced a series of traumatic events. As mentioned above, an extramarital sexual encounter involved crack cocaine and led to the heart attack and death of the woman he was with in the bed right next to him. This was followed by ostracism from his family when they learned of this event, the scope of his substance abuse, and his misuse of the family's financial resources. His wife divorced him, he became estranged from his daughters, and later his ex-wife died of pancreatic cancer. In the context of Geoffrey's anxiety disorder, these accumulating, highly stressful experiences culminated in such self-reported PTSD symptoms as flashbacks, hypervigilance, mistrust of people, and emotional numbing. At the same time, the losses involved - of his marriage, of his relationship with his daughters, and of his self-esteem based on the shame associated with his self-destructive behavior and self-perceived lack of achievement-- seem a major factor in Geoffrey’s depression.

Another factor associated with the maintenance of Geoffrey's depression is his avoidance of social contact, caused by his social anxiety and the lack of energy associated with his depressed state. This then becomes a vicious circle, with anxiety and depression first causing 
social withdrawal, and then the subsequent lack of social contact exacerbating the social anxiety and depression.

Finally, in terms of Persons' (1989) cognitive formulation model, two of the core beliefs underlying the variety of behavioral and emotional problems that Geoffrey developed as an adult would appear to have been the following; "My intensely anxious reaction to situations makes me defective, and so I have to 'aim low' in my expectations of myself and my life," and "I need to escape from my anxiety through alcohol, drugs, and sexual release, not necessarily within my marriage."

\section{$\underline{\text { Factors Leading to Cognitive Problems }}$}

Geoffrey’s deficit in cognitive skills was reflected in his very short attention span, compromised recent memory, distractibility from an attention set, and difficulty speaking or listening while writing. Above, in the Guiding Conception section, a number of causal factors associated with executive skill deficit were mentioned, including depression, advancing age, and a chronic disease like Type II diabetes. All of these factors were present in Geoffrey's case.

\section{Note Regarding Causality}

Note that it is always difficult to identify etiologies of psychiatric symptoms when medical conditions are comorbid, especially in patients who are aging, and it is likely that Geoffrey's symptoms had heterogeneous origins. For instance, patients with Type I or II diabetes are twice as likely to experience depression as those without, and estimated prevalence rates of major depression is $11 \%$ in adults with diabetes (Anderson et al., 2001). Thus, it was unclear if a portion of Geoffrey’s depressive symptoms could be explained by his poorlycontrolled medical condition. Additionally, depression has been found to detrimentally impact diabetes glycemic control (Hassan, Loar, Anderson, \& Heptulla, 2006) and also negatively impacts a patient's attitude towards diabetes and its treatment (Kruse et al., 2006). There is also evidence that aging (West, 1996), depression (Lockwood, Alexopoulos, \& Van Gorp, 2002), past or current drug use (Jentsch \& Taylor, 1999), cultural factors such as quality of education (Rabbitt \& Lowe, 2000), and certain health problems such as diabetes (Stewart \& Liolitsa, 1999) and hypertension (Manolio, Olson, \& Longstreth, 2003) are independent risk factors for executive skills deficits.

\section{Treatment Plan}

\section{$\underline{\text { CBT Treatment Modules }}$}

In light of the assessment and formulation just laid out, interventions were developed to address Geoffrey's subjective anxiety and depression, inactivity, low self esteem, decreased social interaction, underachievement, and cognitive impairment. These interventions came from various cognitive behavior therapy (CBT) modules, as described above in the Guiding Conception section. The interventions included: (a) psychoeducation about mood; (b) selfmonitoring; (c) behavioral activation; (d) in-vivo and imaginal exposure to anxiety provoking 
situations; and (e) cognitive restructuring. More specifically, the modules chosen for the CBT component of Geoffrey's treatment were derived from several well known published manuals, workbooks, and journal articles:

*** Psychoeducation and cognitive restructuring modules were derived from Feeling Good (Burns, 2001) and Mind Over Mood (Greenberger \& Padesky, 1995).

*** Behavioral activation tasks were derived from Depression in Context (Martell, Addis, \& Jacobson, 2001).

*** Exposure exercises for non-PTSD symptoms were derived from Cognitive Behavioral Group Treatment for Social Phobia (Heimberg \& Becker, 2002) and Mastery of Your Specific Phobia (Antony, Craske, \& Barlow, 1995).

*** Exposure tasks for PTSD symptoms were derived from Foa, Hearst-Ikeda, \& Perry (1995).

\section{$\underline{\text { Executive Skills Training Modules }}$}

As mentioned above in the Guiding Conception section, the effectiveness of CBT modules requires basic executive skills. Because of this, and because in addition efficiency was paramount as a guiding principle for treatment, it was of some concern that Geoffrey reported many cognitive symptoms that could potentially interfere with the efficient learning of CBT skills. For instance, he demonstrated a very short attention span, often asking to take breaks during the diagnostic interview and neuropsychological testing. The interviewer had to refresh Geoffrey's memory of the instructions of a subset of the tests, and he was easily distracted by extraneous noises outside the testing room, which occasionally caused him to lose attentional set. He also had difficulty speaking or listening while writing.

With the above in mind, to enhance the impact of the CBT modules on Geoffrey, together with enhancing the quality of his overall life experience, cognitive training was also included in Geoffrey's treatment. This was done by adding treatment modules from Attention Process Training II (APT, CBT/APT; Sohlberg, Johnson, Paule, Raskin, \& Mateer, 2001), a standardized program meant for rehabilitation of frontal lobe injury. As far as we know, this systematic approach to enhancing executive skills has not been used in any previous trials of CBT for latelife mood or anxiety disorders.

We chose APT as the executive skills training component for a number of reasons. It is popular, readily available, easy to administer, and has empirical data to support its efficacy in patient groups. The practice in APT is varied across tasks, which makes the training interesting and challenging. The practice is hierarchically designed such that basic skills are constantly stimulated while newer, more complex skills are targeted and exercised. APT II includes modules that are meant to facilitate the transfer and generalization of skills to new, real life situations. APT II tasks are selected for their ability to target the distinct types of attention that are commonly disrupted in later life (e.g., sustained attention, divided attention; Sohlberg \& Mateer, 2001). The APT program is comprised of audio compact discs and written worksheets that participants can easily use at home without technical support. This is vital, because many 
older patients do not have computers or are not computer-savvy. The difficulty level of each exercise is tailored to each client's abilities. If fewer than $50 \%$ of items are solved correctly on any exercise, then the next exercise is of lesser difficulty. Once $80 \%$ of items or more are solved correctly, then the next exercise is of greater difficulty. A skills generalization module designed to facilitate the use of CBT techniques under naturalistic conditions was also implemented in later sessions.

\section{$\underline{\text { Treatment Procedures }}$}

Both APT and CBT included in-session practice and homework. The cognitive training was practiced with compact discs and written response sheets. The CBT exercises also involved worksheets and reading assignments. Although it is preferable to schedule a mid-week homework troubleshooting phone call to assist clients with independent practice, Geoffrey did not own a telephone; therefore, he agreed to contact the therapist using the telephone at the senior center if he had any questions or problems on the assignments. Geoffrey was asked to bring all his independent work with him to each session so that it could be reviewed, discussed, and photocopied for archival purposes.

The treatment program originally developed for use with Geoffrey included eleven, 90minute sessions over a ten-week period (two sessions per week for the first week followed by one session per week for the remaining weeks). This program was believed to be barely adequate to address the client's many difficulties. On the other hand, it was also believed that some treatment was better than no treatment, and it was unclear whether or not Geoffrey would have been able to obtain care elsewhere in the community. The client and therapist agreed to accomplish as much as possible in the relatively short period of time available for face-to-face sessions, and to check in by telephone at the senior center for subsequent follow up sessions.

\section{COURSE OF THERAPY}

\section{Overview of the Therapy}

\section{Building a Strong Therapeutic Relationship}

Rapport building, assessment, and intervention strategies were interwoven throughout the course of Geoffrey's treatment. Ongoing assessment was integrated into each session through activities such as (a) monitoring performance improvements on cognitive exercises, and (b) reviewing daily mood records completed as homework. With regard to the latter, he rated how depressed, anxious, and pleasant he had felt over the course of each day on a " 0 " to " 8 " scale, with " 0 ” meaning no anxious, depressed, or pleasant moods; and "8” meaning the highest level of anxious, depressed, or and pleasant moods.

Rapport was established early on through reflective listening during the initial assessment and presentation of a credible treatment rationale, and reinforced throughout treatment by a collaborative approach to the implementation and evaluation of treatment strategies. Rapport developed quickly, partly through the client's willingness to take on challenges and the therapist's willingness to keep him focused and moving toward his goals. 
The therapist made a special effort not to treat the client with "kid gloves," specifically to avoid the self-fulfilling prophecy of underachievement that can occur when clinicians (and even older clients) fall prey to lowered expectations based on ageism (e.g., Laidlaw et al., 2003; Unutzer, Katon, Sullivan, \& Miranda, 1999). Overall, the therapist's communication of respect for and belief in Geoffrey seemed to have a very positive impact on his self-esteem, since he viewed the therapist as an educated person who represented the intellectual aspirations Geoffrey once had, but which were thwarted by his anxiety disorder. Also with respect to Geoffrey's earlier aspiration to be a school teacher, the "school like" activities of the therapy in a nonthreatening setting helped to engage him in the venture.

In contrast to Geoffrey's demographic characteristics, the therapist (the first author) was demographically quite different - much younger, white, much more educated, and a female. These differences were discussed with Geoffrey, and he expressed comfort with them. Moreover, the therapist modified her style of communication to match the client's, which in this case meant that she increased her use of slang and humor in sessions. For instance, Geoffrey's treatment took place during the same time that a cultural catchphrase, "What would Jesus do?” was very popular. Geoffrey had heard this phrase used during his prior inpatient treatment for substance dependence. He mentioned that it did not hold any special significance to him since he was not religious, and he even found the phrase somewhat offensive. Together, he and the therapist came up with an alternative that was more meaningful, but conveyed the same overarching message. Geoffrey, who was a long-time fan of comedian Richard Pryor, would ask himself, "What would Richard Pryor do?” and he would then do the opposite, taking into consideration that Pryor's decisions sometimes landed him in chaotic circumstances.

Whenever possible, additional examples from African and African American culture were used to illustrate positive themes that were pertinent to the treatment (e.g., "courage” was illustrated by Magic Johnson and Rosa Parks; “wisdom,” by Martin Luther King; “creativity,” by Miles Davis; “perseverance despite adversity,” by Nelson Mandela and Billie Holiday). This was meant to enhance the client's ability to identify well-known cultural figures who might be useful in perspective-taking exercises (CBT Session 5). Research also suggests that therapists who demonstrate a working knowledge of African American culture and apply this knowledge in therapy sessions are also more likely to effectively accentuate clients' strengths and assets, and less likely to work from a deficit model than those who do not (Neal-Barnett \& Smith, 1996), which could have further enhanced rapport.

\section{$\underline{\text { Structure of Each Session }}$}

Each therapy session lasted for 90 minutes, and consisted of 35 minutes of executive skills training, followed by 35 minutes of CBT exercises, with the remaining time devoted to assigning and reviewing homework. A 5-minute break was taken at the midpoint of each session, between the cognitive training and CBT components. The client used a compact disc player with headphones, worksheets, a hand counting device, and a timer for at-home practice. In session, the cognitive training was administered by computer or by the therapist. The APT training modules were completed first in all sessions. 


\section{APT Training, Sessions 1 and 2}

The first two sessions took place during the first week of treatment. This massed scheme was chosen to increase the number of sessions held during the available ten weeks. Given that session 1 of APT was at the "easy" level, and session 1 of CBT included mostly psychoeducation rather than behavioral skills training, it was believed that two sessions in the first week would not be overwhelming for the client. However, later sessions were held weekly, as APT became more difficult and behavioral exercises meant to be practiced in between sessions were introduced. In sessions 1 and 2, the therapist provided the rationale for executive skills training and led the client through 15 minutes of practice on each of two APT exercises, Mental Math Activity and Alternating Alphabet Stimuli. In Mental Math Activity, the therapist read a sequence of numbers to the client, who applied a target application (e.g., adding two) to each number, then verbally gave back the new series. This task provides practice in the manipulation of information held in working memory. Alternating Alphabet Stimuli required that the client look at a list of letters in the alphabet and alternate between writing the letter in the alphabet that comes just before and the letter that comes just after the target letter on the list. This task requires rapid shifting between two rules. These tasks were also practiced independently for homework.

Geoffrey accepted the rationale for cognitive training, but initially found the APT practice trials difficult. He expressed frustration for the first several minutes, but became more comfortable with the task after the therapist reminded him that the exercises were meant to be practiced repeatedly over time, and that most people do relatively poorly on their first few trials of the tasks. After he began to experience improvement, he regarded the activities more positively, and at the end of session 2, reported that he enjoyed the practice overall. Across the first two practice sessions, his score on Mental Math Activity improved from $10 \%$ to $90 \%$ correct, and his score on Alternating Alphabet Stimuli improved from 25\% to $70 \%$ correct.

\section{CBT, Session 1.}

The CBT component of session 1 included psychoeducation on mood, a description of cognitive-behavioral models of depression and anxiety, followed by a discussion of the first transdiagnostic target of treatment: withdrawal from and avoidance of activities as symptoms of depression and social anxiety. Homework assigned in session 1 consisted of a daily mood record form on which average depression, anxiety, and pleasant emotions were rated on a 0 to 8 scale, 30 minutes of daily APT practice on the same two tasks practiced in the session, and behavioral activation exercises. Specifically, for the first week’s homework, Geoffrey agreed to walk to work rather than take public transportation, and to start a conversation with at least one unfamiliar person every day, either at or on the way to the senior center. He also planned to reduce time spent watching television from 6 to 2 hours per day over the course of the week.

\section{CBT, Session 2}

In session 2, the CBT component consisted of discussions of pleasant-activity scheduling and exposure to anxiety-provoking cues. The client and therapist made a list of potentially pleasant activities that Geoffrey had avoided due to his social anxiety, such as attending a 
political rally or a book-signing at a local bookstore. This strategy allowed us to simultaneously target symptoms of depression and social anxiety. Geoffrey agreed to engage in three pleasant exposure activities from the list over the upcoming week. He also read chapters 1 through 3 in Feeling Good by David Burns (1999), which was provided by the therapist.

\section{APT Training, Sessions 3 and 4}

APT tasks in sessions 3 and 4 were Sentence Stimuli, in which the clinician read a sentence, and the client verbally gave back words in the sentence, starting with the word with the fewest letters and ending with the word with the most letters. Geoffrey performed very well on Sentence Stimuli. In the second task, Sustained Auditory Attention, the participant listened to auditory stimuli on a compact disk and pressed a buzzer to identify target stimuli. Eventually, distracting background noise was added, the pace increased, and targets advanced from simple (e.g., "round objects") to more complex, (e.g., "holidays occurring between the months of January and August”), making the task more difficult. Geoffrey responded very well to Sustained Auditory Attention, and enjoyed the "feeling in his brain" after practice on inhibiting inappropriate responses during the task. He described the practice as "good mental exercise," and his scores improved from 50 to $90 \%$ on Sentence Stimuli, and from 30 to $70 \%$ on Sustained Auditory Attention. He continued to practice the four APT tasks for homework.

\section{CBT, Sessions 3 and 4}

Continuing with our decision to prioritize treatment targets common to mood and anxiety disorders, the CBT phase of sessions 3 and 4 included an introduction to the concept of distorted and automatic thoughts, and basic instruction in cognitive restructuring. A list of cognitive distortions from Feeling Good and the functional analytic thought record from Mind Over Mood were used. In session 3, Geoffrey described several types of distorted cognitions that he had engaged in over the previous week, including all-or-nothing thinking, mind reading, and discounting the positive. He kept a log of such thoughts over the week for homework, and read chapters 4 through 6 in Feeling Good. He generated two new behavioral activation/exposure tasks to practice: make a social visit to his local barbershop and spend time working in the administrative office at the senior center alongside the director, as well as his usual time spent working in the kitchen.

In session 4 Geoffrey showed a sound understanding of the cognitive restructuring technique, but at times had trouble generating evidence that did not support his negative thoughts. He was assigned a minimum of three thought records per day as homework.

\section{APT Training, Sessions 5 and 6}

Sessions 5 through 8 included Article Scan and Logic Problems taken from a test preparation book (Barron's How to Prepare for the GRE by Bobrow [2002]). The Article Scan task required that while silently reading a three or four-paragraph article, the participant cross out specified target stimuli (e.g., the word "and," any word ending with “ed”). Article memory and comprehension were tested at the end of each trial. Each article was re-read until all targets were successfully identified and comprehension questions answered correctly. Logic problems 
required application of principles such as mutual exclusivity and if-then contingencies. The logic problems were more difficult for Geoffrey than the previous APT tasks, requiring more session time to complete. In session 6, the therapist showed him a strategy for mapping out the problems using pencil and paper, which led to improvement in his performance from $30 \%$ to $60 \%$ correct. Both tasks were assigned as homework.

\section{CBT, Sessions 5 and 6}

Review of cognitive restructuring and additional practice took place in sessions 5 and 6 . Because Geoffrey had trouble generating evidence in session 4, an adjunctive perspective-taking technique was also used to assist Geoffrey in subsequent sessions. He was asked to pick three people from contemporary culture (historical or political figures, and/or characters from books, movies, television, or even pets) whom he believed to be good problem solvers, to possess good senses of humor, or to be exceptionally wise. When engaging in cognitive restructuring, Geoffrey was asked to pretend that he was each of the three characters, and to ask himself what evidence each character would provide to help him challenge his negative thoughts. Geoffrey chose Bill Clinton because of his liberal political views; Maya Angelou because of her wisdom; and New York Senator Charles Rangel, whom Geoffrey believed to be a very lively and outspoken politician. We prefer this strategy to the question more commonly used, "What would you tell a friend who had this same problem?” because it helps clients develop the ability to take on the perspectives of others, as opposed to generating more of one's own evidence. This technique was imparted in session 5, and incorporated into the thought record for homework. Geoffrey also planned to reduce television watching time to 1 hour per day, after having successfully reduced it to 2 hours per day.

The therapist noted in session 5 that one aspect of the therapy process was somewhat problematic. Geoffrey often responded, “I don’t know,” to questions asked in session. Although it is entirely possible that he did not know the answer to a subset of these questions, it was hypothesized that excessive use of the phrase might be a subtle form of avoidance of painful or uncomfortable material. In other words, "I don't know" might really mean, "I am unwilling to think about it." The therapist used several strategies to address this tendency, such as requesting, "I realize that you might not know. But let’s pretend for just a moment that you do know, and generate some possible answers," and "Don't worry about being right or wrong, just take some educated guesses." Eventually, Geoffrey realized that his tendency to respond, "I don't know," began as a strategy for dealing with white people whom he didn't fully trust. Over time, however, it had generalized as a way of dealing with all white people. It was also a way to avoid "looking stupid," but the client acknowledged that it had become counterproductive. He agreed that it would be an interesting experiment to try and limit his use of the phrase during sessions, and began an "I don't know" log. To complete the log, he listened to session tapes and kept a tally of the number of times he uttered the phrase. By his count, this logging exercise led to a decrease in his use of the phrase from 22 instances, to 11 instances, to 5 instances across sessions 8 to 10 , with no additional intervention.

In session 6, Geoffrey was able to challenge his negative thoughts through cognitive restructuring with ease, with minimal assistance from the therapist. Some examples of Geoffrey’s restructured thoughts: 
*** The thought, "If I relapse, I may never get sober again,” was restructured to, "Relapse would be unfortunate, and I am doing all I can to stay sober. If I did relapse, I would know where to get help in the community.”

*** The thought, "I ruined my life by using drugs," became "My life is not ruined; I have had a setback that I am working to correct."

*** And the thought, "I am a pathetic human being who will never amount to anything," was modified to, "I do a lot for my friends and the senior center where I volunteer."

*** Geoffrey's neutralized version of "My wife died hating me" was "My wife felt pain due to my actions. However I tried to make it up to her the best that I could."

All the balanced thoughts Geoffrey generated were associated with reductions in negative emotion (e.g., anxiety, guilt, anger, insecurity), and increases in neutral and positive emotions (e.g., calm, complacence, pride).

Geoffrey also reported in session 6 that he had finally worked up the courage to telephone one of his four daughters, with whom he had not had contact for several years. The conversation went well, and she suggested that he might also contact another of his daughters, who said that she often wondered about his current life circumstances. He planned to use cognitive restructuring to prepare for the call, but he would do so without the aid of the worksheet.

\section{APT Training, sessions 7, 8, and 9}

In sessions 7 and 8, the client continued to practice all APT tasks at more advanced levels. In session 9, CBT exercises were substituted for the APT content to facilitate generalization of skills. Learning aids were removed and distracting stimuli were added. For instance, whereas in early sessions the client would engage in a divided attention task such as Article Scan, in later sessions he was asked to alternate quickly between two CBT exercises. Therefore, he practiced the same mental skill but with material that was relevant to the treatment.

Alternatively, whereas in early sessions the client engaged in the Sustained Auditory Attention task with distracting noise in the background, in the later sessions he was asked to complete cognitive restructuring mentally, but with the television volume turned to "loud" to increase his ability to focus attention and overcome distraction. As homework, he continued to practice these generalization tasks independently.

\section{CBT, Session 7}

The therapist and client discussed the importance of social support, and how Geoffrey's relationships with others could be improved, particularly those with his adult daughters. He agreed to begin cultivating one close friendship, and to this end, invited a friend along on one of the social activities he was assigned for homework (i.e., attend a free outdoor jazz concert in a public park). 
Also in session 7, Geoffrey brought up the fact that his diabetes was not well controlled, and that he believed this negatively affected his mood. Together, the therapist and client searched the internet for a study at a local hospital that would provide Geoffrey with a behavioral health case worker who would assist with his self-care regimen, and would provide compensation for participation. He agreed to visit the diabetes clinic weekly, began to monitor his blood sugar daily, scheduled regular checkups, and successfully cut back on smoking. He used the money he earned to purchase a cell phone, which allowed him to improve his relationships with his family and friends. For homework, he planned to attend a political rally and talk to at least three unfamiliar people. He planned to engage in these exercises while simultaneously using cognitive restructuring "on the fly," as needed.

\section{CBT, Sessions 8 and 9}

During session 8, Geoffrey mentioned that he had a job interview in the upcoming week, which resulted in an increase in his anxiety and depression ratings on the mood record from " 0 " to above " 5 " on the " 0 " to " 8 " scale, and a decrease in pleasant ratings from above " 5 " to slightly above "3." Geoffrey was looking forward to the interview, but expected that he would not perform well and would then miss out on an opportunity for gainful employment. The last 15 minutes of the session were devoted to restructuring his negative thoughts about the interview and its outcome.

CBT exercises in sessions 8 and 9 included the development and practice of an exposure hierarchy for targeting Geoffrey's claustrophobic avoidance. Tasks on the hierarchy included placing a paper grocery bag over his head; hyperventilating to bring about suffocating feelings; allowing the therapist to lock him in a supply closet; riding in a small, hot elevator in the building where the senior center was located; and walking up a narrow six-story set of stairs with a low ceiling wearing excessively warm clothing. Each of these tasks were undertaken for increasing durations of time. He practiced these tasks for homework, and agreed to rate his anxiety throughout. Each task was practiced until his rating was a "2" or lower.

\section{APT Training, Session 10}

In session 10, generalization training continued. CBT exercises were substituted for the APT content to facilitate generalization of skills. Learning aids were removed and distracting stimuli were added. These were also assigned as homework.

\section{CBT, Session 10}

The therapist and client engaged in imaginal exposure to the traumatic event involving his female friend's sudden death 6 years earlier. However, Geoffrey found that his memory for the details of the event was poor because drug and alcohol use were involved in the event. He did the best he could given this constraint, and reported that as he repeatedly pictured the scenario in his imagination and described it to the therapist, his anxiety level reduced from a 7 to a 4 on a 0 -to-8 point scale. The client and therapist also reviewed all skills practiced to date. Geoffrey agreed to engage in writing over the following week, focused on recounting the details of the traumatic event. 


\section{Between Session 10 and 11: The Development of a Cue Exposure Therapy (CET) Strategy}

In the week following session 10, Geoffrey received the job offer from the local Department of Parks and Recreation, for which he had interviewed two weeks earlier.

He was very eager to accept the position. However, he realized that the only route to the workplace necessitated that he pass by the same building where he used to purchase and use crack cocaine. Geoffrey was extremely concerned that walking past the building would reactivate cues for using crack and other drugs, and that he would relapse. We spoke with the staff at the hospital where Geoffrey had most recently completed a detoxification program to assess his potential for relapse. After consulting with Geoffrey's former case manager, we collectively decided that the benefits involved with his resuming work would outweigh the risks, especially if we could facilitate habituation to drug cues through exposure before he started the job. We then modified plans for our last week of treatment accordingly to include cue exposure therapy (CET).

CET has been advocated as a potentially effective method of treating the strong reactions, termed cue reactivity, that addicted and post-addicted subjects experience when exposed to stimuli associated with current or historical drug use. A plethora of studies investigating cue reactivity have shown that exposure to drug-related cues (i.e., drug paraphernalia, environmental stimuli) elicits physiological responses such as increased heart rate and tension, and subjective reports of increased desire for drug administration (Carter \& Tiffany, 1999; Foltin \& Haney, 2000; Saladin, Brady, Grapp, \& Rothbaum, 2006). These physiological and subjective changes are presumed to then motivate drug use (Conklin \& Tiffany, 2002). The interpretation of cueinduced reactions elicited by drug-related stimuli is most commonly derived from a classical conditioning learning paradigm (Conklin \& Tiffany, 2002). From this perspective, drug cues (CS), which are those environmental stimuli consistently associated with drug intake (US), are conceptualized to moderate or mediate craving and drug use (CR).

CET, which has been implemented across most drug classes (Lee et al., 2003; Franken, De Hann, Van Der Meer, Haffmans, \& Hendriks, 1999; Monti et al., 1993), aims to extinguish cue reactivity in addicts and post-addicts via systematic, repeated, unreinforced exposure to drug-related cues. Although the empirical findings on the efficacy of CET have been mixed (for a review, see Conklin \& Tiffany, 2002), several studies found that CET led to significant reductions on both objective and subjective indices of cue reactivity, and concomitant reductions in drug use, in various drug addicted and post-addicted populations, including recovering cocaine dependent adults, smokers, alcoholics, and opiate users (e.g., O’Brien, Childress, McLellan, \& Ehrman, 1990, Drummond \& Glautier,1994; Franken, et al., 1999; Lee et al., 2004).

Some evidence suggests that CET is most effective when ecologically valid cues are used through in vivo exposure, or virtual reality models (e.g., Lee et al., 2004). This finding is consistent with animal research indicating that relapse may be mitigated by conducting cue exposure in the initial conditioning environment (Bouton, 1994). As such, it was hypothesized that Geoffrey's cue reactivity would likely attenuate via unreinforced, systematic cue exposure conducted in view of the actual setting in which he formerly bought and used drugs. 


\section{Sessions 11 through 14}

In session 11, we immediately shifted the focus of Geoffrey's treatment to therapistassisted CET focused on the building en route to his new job. Due to the time constraints posed by the therapist's impending move to another city, four daily sessions were planned for the final week of treatment. Geoffrey's exposure hierarchy included a range of tasks in ascending order of difficulty:

*** walk past building quickly with therapist; walk past building slowly with therapist;

*** stop walking and stand in front of building for two minutes;

*** stop walking and stand in front of building for five minutes; and

*** stop walking and stand in front of building for 15 minutes.

Geoffrey then practiced this set of tasks while the therapist observed from the building next door, then from across street, then from down the block and across the street, then from two blocks away.

Geoffrey verbalized his thoughts and emotions and rated his mood before, during and immediately following each exposure trial. He experienced strong feelings of arousal, including a knot in his stomach, mild stomach cramps, a rapid heart rate, and increased rate of breathing in the first 20 minutes of the first day of practice. He also reported several vivid mental images of drug paraphernalia and depictions of himself using crack at the start of the exposure exercises. He described his mood as "very anxious," and he rated the first two passes at an 8, the maximum rating possible on the scale. Over the four days of practicing the tasks repeatedly, however, his ratings decreased substantially and on the final day of treatment, Geoffrey was able to complete the most challenging task with an anxiety rating of 3.

When the therapist and client terminated the following week, Geoffrey chose to continue with partner-assisted exposure. The efficacy of partner-assisted exposure has been shown to be equivalent to unassisted exposure for the treatment of agoraphobia and obsessive-compulsive disorder (Baucom, Shoham, Mueser, Daiuto, \& Stickle, 1998; Daiuto, Baucom, Epstein, \& Dutton, 1998). Only one study has evaluated an assisted exposure treatment utilizing nonromantic partners. In this study, agoraphobic married women exhibited comparable improvements regardless of whether they participated in exposure treatment with their husbands or a female friend (Oatley \& Hodgson, 1987).

With the above in mind, Geoffrey's decision to continue with partner-assisted exposure was encouraged to enhance social support after the therapist's departure. We discussed whom he might select as an exposure partner. Due to his long-term social isolation, there were few potential candidates to assist in his treatment. The obvious choice seemed to be his newlycultivated friend Mitchell. Mitchell agreed to act as his exposure coach and accompany him to his new job during his first week of employment. The therapist and client agreed to speak by telephone once per day during the week to debrief the additional exposure practice. 
The partner-assisted exposure went well for the first four days. However, on the last day of the week, Mitchell was not at the appointed meeting place to accompany Geoffrey to work, and Geoffrey proceeded alone, which he said was not difficult. His anxiety dropped from 4 to 2 during partner-assisted exposure with Mitchell. During his second week of work he walked by the building alone with anxiety rating of 1 . At this point, he felt confident that he could walk unaccompanied without difficulty.

Although Geoffrey responded well to the exposure exercises, we soon learned that Mitchell was less fortunate. Unbeknownst to us, Mitchell also had a history of crack cocaine abuse. The week following partner-assisted exposure, Geoffrey learned that while walking home from assisting him, Mitchell was approached by a drug dealer, purchased crack cocaine, and relapsed. Although this news was initially devastating, Geoffrey came to view it as an opportunity to repay Mitchell for his help and friendship by assisting him in finding a detoxification program and supporting him during his treatment.

\section{Phone Contact After Face-to-Face Sessions Ended}

Due to the therapist's move to another city, the therapist and client had several conversations by telephone over the course of the next few days, focused specifically on the situation with Mitchell, and on inoculating Geoffrey against a similar outcome. Phone sessions were chosen by the client over a referral to another therapist, perhaps due to the success and intensity of the treatment and the ease with which the therapist and client had developed rapport. This arrangement was agreed upon tentatively, with ongoing evaluation of Geoffrey's need for additional face-to-face therapy conducted each week by the client and thearpist.

During phone sessions, the therapist focused on increasing Geoffrey's confidence and emphasized that he would be the most likely person to persuade Mitchell to seek help. In addition to locating an inpatient detoxification program, Geoffrey accompanied Mitchell to a support group at a local hospital and helped him secure a case manager. Geoffrey called me several times each week for the month following this event, and our phone sessions focused mostly on cognitive restructuring, debriefing the situation involving Mitchell, and maintaining the benefits Geoffrey had derived from exposure.

The therapist and client conducted six, monthly booster sessions by telephone, focused on maintaining benefits derived from the treatment. Each session consisted of a check of the month's events and Geoffrey's mood, a review of skills learned in therapy, and a discussion of strategies for enhancing benefits through continued practice. In the final phone session with Geoffrey, we learned that Mitchell successfully finished a detoxification program and received a V.A. stipend to obtain a low-cost studio apartment.

After the final booster session, a SCID interview was administered over the phone by a graduate student assessor. The client's multiaxial summary from the full course of treatment pre-treatment, post-treatment, and at six-month follow-up -- appears in Table 3. 


\section{MONITORING AND THE USE OF FEEDBACK INFORMATION}

The Beck Depression Inventory (BDI; Beck \& Steer, 1987), the Stroop Test of Color Word Interference (Stroop CW; Trenerry et al., 1989), and the 0-8 mood ratings on how depressed, anxious, and pleasant Geoffrey had felt over a day were the primary sources of symptom monitoring during the course of treatment. The BDI and Stroop CW were administered in each session, and the mood ratings were made daily by the client. Given the relation between mood disorders and cognitive deficits, we wanted to track changes in depression relative to changes in executive functioning. Figure 1 provides a temporal timeline for changes in these two domains. While causal inferences cannot be drawn from these data, it appears unlikely that changes in mood were the cause of Geoffrey's cognitive improvements. Instead, it appears that cognitive improvement preceded, and potentially contributed to, the improvement in depressive symptoms, or alternately that a third variable contributed to changes in both mood and cognition.

Daily mood ratings collapsed over the lag between each session are displayed in Figure 2, and show evidence of a decrease in anxiety and depression accompanied by an increase in pleasant moods over the course of treatment. The patterns of change were not necessarily linear, however, suggesting that although Geoffrey's status had clearly improved, his moods did not appear to be stable at the time of the therapist's departure. Therefore, continued practice of CBT techniques was the focus of the six subsequent telephone booster sessions.

\section{CONCLUDING EVALUATION OF THE THERAPY'S PROCESS AND OUTCOME}

\section{Indicators of Outcome}

\section{Quantitative Measures}

Quantitative measures of outcome are shown in the Tables 1-3 below. In summary,

*** Table 1 shows change from Geoffrey's pretreatment to post-treatment scores on two measures of depression (the Beck Depression inventory [BDI] and the Geriatric Suicidal Ideation Scale [GSIS]); and on three measures of anxiety (the Social Anxiety Interaction scale [SAIS], the Beck Anxiety Scale [BAI], and the State-Trait Anxiety Inventory - Trait [STAI]).

*** Table 2 shows Geoffrey’s pre-treatment to post-treatment changes on six measures of cognitive functioning that tap short-term memory, associative memory, sustained attention, inhibitory control, verbal fluency, and concept formation.

*** Table 3 shows Geoffrey’s formal, multiaxial DSM diagnoses (American Psychiatric Association, 2000) at pre-treatment, post-treatment, and six-month follow up (via SCID interview administered over the phone). 
A post-treatment assessment indicated that Geoffrey improved considerably on all mood and neuropsychological outcome measures. For example, as shown in Table 1, on the Beck Depression Inventory, he successfully reduced depressive symptoms from the "severe" range to the "mild” range (Beck \& Steer, 1987) over the ten weeks of treatment. Also, Table 1 shows that he overcame most of the symptoms of social anxiety disorder, although he reported lingering mild (but tolerable) feelings of nervousness at meetings and gatherings with unfamiliar people.

Himadi, Boyce, and Barlow’s (1986) criteria were applied to assess whether changes within an individual case on outcome measures should be considered clinically significant. Criteria require that the client be free of DSM diagnoses and show at least a $20 \%$ decrease from pretest on at least $75 \%$ (or in this case $80 \%$, four out of five measures) of outcome measures. This criterion is not as stringent as other published guidelines for assessing clinically significant improvement (3.g., Jacobson \& Truax, 1991). However several authors note that improvement in psychotherapy with older adults is typically less dramatic than what is seen in younger adults, possibly due to confounding factors such as symptoms of aging, and thus the use of a more liberal criterion might be appropriate (e.g., Stanley, Beck, et al., 2003; Wetherell et al., 2003). This might be especially appropriate when the BDI is used as the primary measure of outcome, because the measure appears to tap somatic symptoms of aging in addition to symptoms of depression (Gallagher-Thompson et al., 2001, Mohlman et al., 2003).

Using Himadi, Boyce, and Barlow's liberal criteria, Geoffrey could be considered a responder to the intervention, having been free of clinical levels of depression and social anxiety at posttreatment according to the SCID (see Table 3), and showing reductions of 64\%, 51\%, $59 \%, 81 \%$, and 30\%, respectively, on all five self-report measures (BDI, GSIS, BAI, STAI, and SAIS; see Table 1).

We also applied Borkovec and Costello's (1993) more stringent criteria for high end-state functioning within the individual case, which requires that the post-treatment score be within one standard deviation of the normal mean on each outcome measure. Applying this more conservative index, Geoffrey met criteria for high end-state functioning on the GSIS, SAIS, and BAI, and scored near this range on the BDI and STAI. His cognitive skills (executive skills in particular) also showed improvement, as shown in Table 2.

\section{Qualitative Measures}

At the end of therapy, Geoffrey reported a noticeable improvement in his mood and the quality of his life. He felt more energized and outgoing, could think more clearly, enjoyed rather than dreaded the complexities of daily life, gained confidence, increased his social circle and interpersonal skills, and was enjoying his new job. His posttreatment goals were to maintain emotional benefits by using the techniques he learned in therapy, continue to work at his new job, and attend courses at an educational facility for older adults. He planned to save money for a larger apartment, afford more social activities, read frequently, and continue to attend meetings of local, political activist groups. Geoffrey was especially pleased to have resumed contact with two of his four adult daughters, and believed that he could not have accomplished this without the aid of CBT exercises. To the therapist's pleasant surprise, at the end of the therapy, Geoffrey 
also asked to keep the APT supplies, worksheets, and GRE Preparation Book to continue independent executive skills training.

\section{Discussion}

We believe that there is much to be learned from the case of Geoffrey. First was our observation that he was representative of a new cohort of older adults in the U.S. Geoffrey was motivated, socially aware, and knowledgeable about mental health and CBT. This made him a particularly appealing client. He was also easy to work with, trusting in the therapy and the therapist, and eager to participate in the activities of the therapy. These factors might have had a positive impact on the ultimate outcome of the case, and contrast sharply with common beliefs about the elderly (e.g., that they are prone to stigma regarding mental health issues, and that depression in the elderly is normal).

As is common in older adults, Geoffrey was faced with a number of challenging life situations (e.g., medical illness, limited finances, and limited family and social support) as well as comorbid anxiety and mood disorders. This made it difficult to ascertain the origin or maintenance factors of his mood and cognitive problems. For instance, both poorly controlled diabetes and prior substance dependence are potential contributing factors to depression, anxiety, and cognitive impairment. On the other hand, poor cognitive control has been associated with increased negative moods and might increase risk for emotional disorders. It was therefore difficult, if not impossible, to identify the causal direction of Geoffrey's symptoms. We thus used a transdiagnostic approach and chose techniques that might affect multiple symptoms, or those symptoms that were shared by two or more disorders. This strategy appeared to be effective, as Geoffrey reported fewer negative mood symptoms, improved his cognitive functions, and gained control over his health problems as a result of the relatively brief intervention.

There were several potential obstacles to treatment, including Geoffrey's lack of transportation and a telephone. Interestingly, however, both ended up leading to positive outcomes. The lack of an automobile made it difficult for him to attend sessions in inclement weather, a problem that was solved by meeting in places that were close to his home, such as the senior center where he worked. Although this occasionally meant that our sessions were somewhat less private than they would have been in the therapist's office, Geoffrey had no concerns about this aspect of treatment, and was appreciative of the therapist's flexibility in finding suitable alternate locations.

Interestingly, his lack of a car also gave rise to the need for intensive exposure therapy (i.e., walking past the building where he used to buy and use crack cocaine) upon receiving the job offer, which was a positive aspect of our work. Although Geoffrey did not have a telephone, he solved this problem by participating in a paid research study. This in turn helped him to stabilize his medical condition, which was another tertiary benefit of the treatment.

Without the initial obstacles, we might not have achieved either of these positive results, namely the benefits of the exposure and his enhanced self-care for diabetes. Even his friend Mitchell's relapse, which was clearly an unintended iatrogenic effect of the treatment, provided 
Geoffrey with a means of enhancing his benefits. One of the primary goals in CBT is to teach the client to "function as their own therapist," but it is not always the case that a client is faced with such a stringent test of his recently acquired therapeutic skills as was Geoffrey. His ability to use his newly developed skills to help a friend contributed to his perception of a positive outcome and increased his overall self-efficacy. And we will certainly be more mindful of possible negative tertiary outcomes when assisting future clients in choosing exposure partners for independent practice.

In summary, the case of Geoffrey was quite complex and challenging, but also very rewarding. Noteworthy aspects of the case included its relevance to the current aging trend in the U.S.; the possible impact of age-related conditions on the cognitive and emotional functioning of older adults; the successful use of a combined transdiagnostic intervention; and specific aspects of the therapy process and course. Additional case studies from the upcoming baby boomer cohort are needed to bridge the gap in our knowledge of how to best serve their needs, especially given the major shift in the U.S. demographic and the lag in relevant mental health research.

\section{REFERENCES}

Adili, F., Larijani, B., \& Haghighatpanah, M. (2006). Diabetic patients - Psychological aspects. In Diabetes mellitus and its complications (pp. 329-349). Oxford: Blackwell Publishing.

Alexopoulos, G. S., Meyers, B. S., Young, R. C., Campbell, S., Silbersweig, D., \& Charleson, M. (1997). “Vascular depression” hypothesis. Archives of General Psychiatry, 54, 915922.

American Psychiatric Association. (2000) Diagnostic and statistical manual of mental disorders - text revision ( $4^{\text {th }}$ ed.). Washington, DC: APA.

Anderson RJ, American Psychiatric Association. (2000) Diagnostic and statistical manual of mental disorders - text revision ( $4^{\text {th }}$ ed.). Washington, DC: APA.

Anderson RJ, Freedland KE, Clouse RE, Lustman PJ (2001), The prevalence of comorbid depression in adults with diabetes: a meta-analysis. Diabetes Care, 24,1069-1078.

Antony, M. M., Craske, M. G., \& Barlow, D. H. (1995). Mastery of your specific phobia: Client workbook. New York: Oxford University Press.

Barlow, D.H. (Ed.). (2007). Clinical handbook of psychological disorders, fourth edition: A stepby-step treatment manual. New York: Guilford.

Barlow, D. H., Allen, L. B., Choate, M. L. (2003). Cognitive-behavioral group treatment for anxiety: A new treatment paradigm. In: Norton P.J., chair. Integrative treatment approaches across anxiety and related disorders. Symposium presented at the annual meeting of the Anxiety Disorders Association of America, Toronto.

Baucom, D. H., Shoham, V., Mueser, K. T., Daiuto, A. D., \& Stickle, T. R. (1998). Empirically supported couple and family interventions for marital distress and adult mental health problems. Journal of Consulting and Clinical Psychology, 66, 53-88.

Beck, A. T., \& Steer, R. A. (1987). Manual for the Beck Depression Inventory. San Antonio, TX: the Psychological Corporation.

Beck, A. T., \& Steer, R. A. (1990). Manual for the Beck Anxiety Inventory. San Antonio, TX: Psychological Corporation. 
J. Mohlman, L.A. Cedeno, R.B. Price, E.B. Hekler, G.W. Yan, \& D.B. Fishman

Pragmatic Case Studies in Psychotherapy, http://pcsp.libraries.rutgers.edu

Volume 4, Module 3, Article 1, pp. 1-39, 08-25-08 [copyright by authors]

Bell, M., Bryson, G., Greig, J., Corocoran, C., \& Wexler, B. (2001). Neurocognitive enhancement therapy with work therapy. Archives of General Psychiatry, 58, 763-768.

Bell, M., Fiszdon, J., Bryson, \& Wexler, B. (2004). Effects of neurocognitive enhancement therapy in schizophrenia: Normalisation of memory performance. Cognitive Neuropsychiatry, 9, 199-211.

Blazer D. G. (2003). Depression in late life: Review and commentary. Journal of Gerontology: Medical Sciences, 56A, 249-65.

Blow, F. C., \& Oslin, D. W. (2003). Late life addictions. In Alan M. Mellow (Ed.) Geriatric psychiatry. Review of psychiatry, vol.22 no.4 (pp. 111-143). Washington, D.C.: American Psychiatric Publishing.

Bobrow, J. (2002). How to prepare for the LSAT law school admissions test. Hauppage, NY: Barrons Educational Series.

Borkovec, T. D., \& Costello, E. (1993). Efficacy of applied relaxation and cognitive behavioral therapy in the treatment of generalized anxiety disorder. Journal of Consulting and Clinical Psychology, 61, 611-619.

Braunschweig, H. M. (2004). The aging of the "baby boom" generation: The potential for increased alcohol use and the need for concern. Dissertation Abstracts International: Section B: The Sciences and Engineering, 64, 6361.

Brown, T. A., Antony, M. M., \& Barlow, D. H. (1995). Diagnostic comorbidity in panic disorder: Effect on treatment outcome and course of comorbid diagnoses following treatment. Journal of Consulting and Clinical Psychology, 63, 408-418.

Brown, T.A., \& Barlow, D. H. (2005). Dimensional versus categorical classification of mental disorders in the fifth edition of the Diagnostic and Statistical Manual of Mental Disorders and beyond: Comment on the special section. Journal of Abnormal Psychology, 114, 551-556.

Bouton, M. E. (1994). Condition, remembering, and forgetting. Journal of Experimental Psychology: Animal Behavior Processes, 20, 219-231.

Burns, D. D. (1999). Feeling good; The new mood therapy. New York: Harper Collins.

Carstensen, L. L., Gross, J, \& Fung, H. (1997). The social context of emotion. In Schaie, K. W., Lawton, M. P. (eds.) Annual Review of Geriatrics and Gerontology, 17, 325-352.

Carter, B. L., Tiffany, S. T. (1999). Meta-analysis of cue-reactivity in addiction research. Addiction, 94, 3, 327-340.

Clark, L.A. (2005). Temperament as a unifying basis for personality and psychopathology. Journal of Abnormal Psychology, 114, 505-521.

Clark, L. A., \& Watson, D. (1991). A tripartite model of anxiety and depression: Psychometric evidence and taxonomic implications. Journal of Abnormal Psychology, 100, 316-336.

Conklin, C. A., \& Tiffany, S. T. (2002). Applying extinction research and theory to cue-exposure addiction treatments. Addiction, 97, 155-161.

Conwell, Y. (2001). Suicide in later life: A review and recommendations for prevention. Suicide and Life Threatening Behavior, 31, 32-47.

Cook, J. M., Orvaschel, H., Simco, E., Hersen, M., \& Joiner, T. (2004). A test of the tripartite model of depression and anxiety in older adult psychiatric outpatients. Psychology and Aging, 19, 444-451. 
J. Mohlman, L.A. Cedeno, R.B. Price, E.B. Hekler, G.W. Yan, \& D.B. Fishman

Pragmatic Case Studies in Psychotherapy, http://pcsp.libraries.rutgers.edu

Volume 4, Module 3, Article 1, pp. 1-39, 08-25-08 [copyright by authors]

Dauto, A., D., Baucom, D. H., Epstein, N., \& Dutton, S. S. (1998). The application of behavioral couples therapy to the assessment and treatment of agoraphobia: Implications of empirical research. Clinical Psychology Review, 18, 663-687.

Drummond, D. C, \& Glautier, S. (1994). A controlled trial of cue exposure treatment in alcohol dependence. Journal of Consulting and Clinical psychology, 41, 809-17.

Erickson, D. H. (2003). Group Cognitive behavioral therapy for heterogeneous anxiety disorders. Cognitive Behaviour Therapy, 32, 179-186.

Fals-Stewart, W. Computer assisted cognitive rehabilitation with drug abusers. Paper presented at the $9^{\text {th }}$ Annual meeting, Cognitive Rehabilitation in Psychiatry, June, 2006.

Feil, D., Marmon, T., \& Unutzer, J. (2003). Cognitive impairment, chronic medical illness, and risk of mortality in an elderly cohort. American Journal of Geriatric Psychiatry, 11(5), 551-560.

First, M. B., Gibbon, M., Spitzer, R. L., \& Williams, J. B. W. (1995). Structured clinical interview for DSM-IV Axis I disorders. (SCID-I, version 2.0, October 1995, Final Version). Biometrics Department, New York State Psychiatric Institute, New York.

Fiszdon, J. M., Bryson, G. J., Wexler, B. E., \& Bell, M. D. (2004). Durability of cognitive remediation training in schizophrenia: performance on two memory tasks at 6-month and 12-month follow-up. Psychiatry Research, 125, 1-7.

Flint, A. (1994). Epidemiology and comorbidity of anxiety disorders in the elderly. American Journal of Psychiatry, 151, 640-649.

Foa, E. B., Hearst-Ikeda, D., \& Perry, K. J. (1995). Evaluation of a brief cognitive-behavioral program for the prevention of chronic PTSD in recent assault victims. Journal of Consulting and Clinical Psychology, 62, 948-955.

Foltin, R. W., \& Haney, M. (2000). Conditioned effects of environmental stimuli paired with smoked cocaine in humans. Psychopharmacology, 149, 24-33.

Franken, I. H. A., De Haan, H. A., Van Der Meer, C. W., Haffmans, J., \& Hendriks, V. M. (1999). Cue reactivity and effects of cue exposure in abstinent posttreatment drug users. Journal of Substance Abuse Treatment, 16, 1, 81-85.

Fuster, J. M. (1997). The prefrontal cortex (3rd ed.) Philadelphia, PA: Lippincott-Raven.

Gallagher-Thompson, D, McKibbin, C, Koonce-Volwiler, et al. (2001). Psychotherapy with older adults. In C.R. Snyder and R.E. Ingram (eds.) Handbook of psychological change (pp 614-637). New York NY: John Wiley \& Sons.

Gallo, J. L., Ryan, S. D., \& Ford, D. (1999). Attitudes, knowledge, and behavior of family physicians regarding depression in late life. Archives of Family Medicine, 8, 249-256.

Gillis, M. M., Haaga, D. A. F., \& Ford, G. T. (1995). Normative values for the Beck Anxiety Inventory, Fear Questionnaire, Penn State Worry Questionnaire, and Social Phobia and Anxiety Inventory. Psychological Assessment, 7, 450-455.

Gist, Y. J., \& Hetzel, L. I. (2004). U.S. Census Bureau, We the people: aging in the United States. Washington DC: US Government Printing Office.

Goldman-Rakic, P. S., \& Brown, R. M. (1981). Regional changes of monoamines in cerebral cortex and subcortical structures of aging rhesus monkeys. Neuroscience, 6, 177-187.

Greenberger, D., \& Padesky, C. A. (1995). Mind over mood; A cognitive therapy manual for clients. New York: Guilford.

Hachinski, V. C., Potter, P., \& Merskey, H. (1987). Leuko-araiosis. Archives of Neurology, 44, 21-23.Lawton, M. P. (eds.) Annual Review of Geriatrics and Gerontology, 17, 325-352. 
J. Mohlman, L.A. Cedeno, R.B. Price, E.B. Hekler, G.W. Yan, \& D.B. Fishman

Pragmatic Case Studies in Psychotherapy, http://pcsp.libraries.rutgers.edu

Volume 4, Module 3, Article 1, pp. 1-39, 08-25-08 [copyright by authors]

Hassan, K., Loar, R., Anderson, B. J., \& Heptulla, R. A. (2006). The role of socioeconomic status, depression, quality of life, and glycemic control in type 1 diabetes mellitus. Journal of Pediatrics, 149(4), 526-531.

Hassing, L. B., Grant, M. D., Hofer, S. M., Pedersen, N. L., Nilsson, S. E., Berg, S., et al. (2004). Type 2 diabetes mellitus contributes to cognitive decline in old age: A longitudinal population-based study. Journal of the International Neuropsychological Society, 10(4), 599-607.

Heimberg, R. G., \& Becker, R. F. (2002). Cognitive behavioral group therapy for social phobia. New York: Guilford.

Himadi, W. G., Boyce, R., \& Barlow, D. H. (1986). Assessment of agorpahobia II: Measurement of clinical change. Behaviour Research \& Therapy, 24, 321-332.

Jacobson, N. S. \& Truax, P. (1991). Clinical significance: A statistical approach to defining meaningful change in psychotherapy research. Journal of Consulting and Clinical Psychology, 59, 12-19.

Jentsch, J. D., \& Taylor, J. R. (1999). Impulsivity resulting from frontostriatal dysfunction in drug abuse; Implications for the control of behavior by reward-related stimuli. Psychopharmacology, 146, 373-390.

Jeste, D. V., Alexopoulos, G. S., Bartels, S. J., Cummings, J. L., Gallo, J. J., Gottlieb, G. L., Halpain, M. C., Palmer, B. W., Patterson, T. L., Reynolds, C. F., \& Lebowitz, B. D. (1999). Consensus statement on the upcoming crisis in geriatric mental health. Archives of General Psychiatry, 56, 848-853.

Kinder, L. S., Katon, W. J., Ludman, E., Russo, J., Simon, G., Lin, E. H. B., et al. (2006). Improving depression care in patients with diabetes and multiple complications. Journal of General Internal Medicine, 21(10), 1036-1041.

Kinsella, K., \& Velkoff, V. A. (2001). U.S. Census Bureau, Series 95/0-1, An Aging World. Washington DC: US Government Printing Office.

Klerman, G. L., \& Weissman, M. M. (1989). Increasing rates of depression. The Journal of the American Medical Association, 261, 2229-2235.

Kruse, J., Petrak, F., Herpertz, S., Albus, C., Lange, K., \& Kulzer, B. (2006). Diabetes and depression - a life-endangering interaction. Zeitschrift Fur Psychosomatische Medizin Und Psychotherapie, 52, 289-309.

Laidlaw, K., Thompson, L. W., Dick-Siskin, L., \& Gallagher-Thompson, D. (2003). Cognitive behaviour therapy with older people. Chichester, West Sussex, England: Wiley.

Laposa, J., Janeck, A., Erickson, D., \& Tallman, K. (2003) Group CBT for heterogeneous anxiety disorders: Preliminary evidence for effectiveness. Presentation to the $31^{\text {st }}$ annual convention of the British Association for Behavioural and Cognitive Psychotherapies, York, England.

Lee, J. H., Ku, J., Kim, K., Kim, B., Kim, I. Y., Yang, B., Kim, S. H., Wiederhold, B. K., Wiederhold, M. D., Park, D., Lim, Y., \& Kim, S. I. (2003). Experimental application of virtual reality for nicotine craving through cue exposure. CyberPsychology \& Behavior, 6, 3, 275-280.

Lee, J., Lim, Y., Graham, S. J., Kim, G., Wiederhold, B. K., Wiederhold, M. D., Kim, I. Y., \& Kim, S. I. (2004). Nicotine craving and cue exposure therapy by using virtual environments. CyberPsychology \& Behavior, 7, 6, 705-713. 
Lezak, M. D., Howieson, D. B., \& Loring, D. (2004). Neuropsychological assessment. Oxford University Press.

Lehmann, S. W. (2003). Psychiatric disorders in older women. International Review of Psychiatry, 15, 269-279.

Lockwood, K. A., Alexopoulos, G. S., \& VanGorp, W. G. (2002). Eecutive dysfunction in geriatric depression. American Journal of Psychiatry, 159, 1119-1126.

Lopez-Luengo, B., \& Vazquez, C. (2003). Effects of Attention Process Training II on cognitive functioning of schizophrenic patients. Psychiatry Research, 119, 41-53.

Mamdani, M., Rapoport, M., Shulman, K. I., Herrmann, N., \& Rochon, P. A. (2005). Mental health-related drug utilization among older adults: Prevalence, trends, and costs. American Journal of Geriatric Psychiatry, 13, 892-900.

Manolio, T. A., Olson, J., \& Longstreth, W. T. (2003). Hypertension and cognitive function: Pathophysiologic effects of hypertension on the brain. Current Hypertension Reports, 5, 255-261.

Martell, C. R., Addis, M., \& Jacobson, N. S. (2001). Depression in context: Strategies for guided action. New York: W. W. Norton \& Co.

Mast, B. T., Yochim, B., MacNeill, S. E., \& Lichtenberg, P. A. (2004). Risk factors for geriatric depression: the importance of executive functioning within the vascular depression hypothesis. Journals of Gerontology: Series A: Biological Sciences and Medical Sciences, 59A(12), 1290-1294.

Mattick, R. P., \& Clarke, J. C. (1998). Development and validation of measures of social phobia scrutiny fear and social interaction anxiety. Behavior Research and Therapy, 36, 455-470.

McIntosh, J. L. (1994). Generational analyses of suicide baby boomers and 13ers. Suicide and Life-Threatening Behavior, 24, 334-342.

Miller, E. (1984). Verbal fluency as a function of a measure of verbal intelligence in relation to different types of pathology. British Journal of Clinical Psychology, 23, 53-57.

Mineka, S., Watson, D., \& Clark, L.A. (1998). Comorbidity of anxiety and unipolar mood disorders. In J. T. Spence, J. M. Darley, \& D. J. Foss (Eds.), Annual review of psychology (pp. 377-412). Palo Alto: Annual Reviews.

Mitte, K. (2005). Meta-analysis of cognitive behavioral treatments for generalized anxiety disorder: A comparison with pharmacotherapy. Psychological Bulletin, 131, 785-795.

Mohlman, J. ( in press). More power to the executive? A pilot test of CBT plus executive training. Cognitive and Behavioral Practice.

Mohlman, J. (2005). Does executive dysfunction impact treatment outcome in late life mood and anxiety disorders? Journal of Geriatric Psychiatry and Neurology, 18, 97-108.

Mohlman, J. (2004). Psychosocial treatment of late life generalized anxiety disorder: Current status and future directions. Clinical Psychology Review, 24, 149-169.

Mohlman, J., Gorenstein, E. E., Kleber, M., deJesus, M., Gorman, J. M., \& Papp, L. A. (2003). Standard and enhanced cognitive behavior therapy for late life generalized anxiety disorder: Two pilot investigations. American Journal of Geriatric Psychiatry, 11, 24-32.

Mohlman, J. \& Gorman, J. M. (2005). The role of executive functioning in CBT: A pilot study with anxious older adults. Behaviour Research and Therapy, 43, 447-465. 
Monti, P. M., Rohsenow, D. J., Rubonis, A. V., Niaura, R. S., Sirota, A. D., Colby, S. M., et al. (1993). Cue exposure with coping skills treatment for male alcoholics: A preliminary investigation. Journal of Consulting and Clinical psychology, 61, 1011-1019.

Morris, R. G., \& Morris, L. W. (1991). Cognitive and behavioural approaches with the depressed elderly. International Journal of Geriatric Psychiatry, 6, 407-413.

Neal-Barnett, A. M., \& Smith, J. (1996). African Americans. In S. Friedman (ed.) Cultural issues in the treatment of anxiety (pp. 154-174). New York: Guilford.

Norman, D. A. \& Shallice, T. (1986). Attention to action: Willed and automatic control of behavior. In R. J. Davidson, G. E. Schwarts, \& D. Shapiro (Eds.), Consciousness and self-regulation: Advances in research and therapy (pp. 1-18). New York: Plenum Press.

Norton, P. J., Hayes, S. A., \& Hope, D. A. (2005). Effects of a transdiagnostic group treatment for anxiety on secondary depression. Depression and Anxiety, 20, 198-202.

O’Brien, C. P., Childress, A. R., McLellan, T., \& Ehrman, R. (1990). Integrating systematic cue exposure with standard treatment in recovering drug dependent patients. Addictive Behaviors, 15, 355-365.

Oatley, K., \& Hodgson, D. (1987). Influence of husbands on the outcome of their agoraphobic wives' therapy. British Journal of Psychiatry, 150, 380-386.

Persons, J.B. (1989). Cognitive therapy in practice: A case formulation approach. New York: Guilford.

Rabbitt, P, \& Lowe, C. (2000). Patterns of cognitive aging. Psychological Research, 63, 308316.

Reynolds, C. F., \& Gatz, M. (2003). Research training in mental health and aging: The harvest is plentiful; The laborers, few. American Journal of Geriatric Psychiatry, 3, 267-270.

Robins, L. N., \& Regier, D. A. (1991). Psychiatric disorders in America: The Epidemiologic Catchment Area Study. New York, NJ: The Free Press.

Saladin, M. E., Brady, K. T., Graap, K., \& Rothbaum, B. O. (2006). A preliminary report on the use of virtual reality technology to elicit craving and cue reactivity in cocaine dependent individuals. Addictive Behaviors, 31, 1881-1894.

Saxby, B. K., Harrington, F., McKeith, I. G., Wesnes, K., \& Ford, G. A. (2003). Effects of hypertension on attention, memory, and executive function in older adults. Health Psychology, 22(6), 587-591.

Schmitz, N., Thefeld, W., \& Kruse, J. (2006). Mental disorders and hypertension: Factors associated with awareness and treatment of hypertension in the general population of Germany. Psychosomatic Medicine, 68(2), 246-252.

Siegle, G. J., Ghinassi, F., \& Thase, M. E. (2007). Neurobehavioral therapies in the $21^{\text {st }}$ century: Summary of an emerging field and an extended example of cognitive control training for depression. Cognitive Therapy and Researc, 31, 265-262.

Silverstein, S. M., Hatashita-Wong, M., Solar, B. A., Uhlhaas, P., Landa, Y., Wilkness, S. M., et al. (2005). Effectiveness of a two-phase cognitive rehabilitation intervention for severely impaired schizophrenia patients. Psychological Medicine, 35, 829-837.

Sohlberg, M. M., Johnson, L., Paule, L., Raskin, S. A., \& Mateer, C. A. (2001). Attention Process Training-II. Wake Forest, N.C.: Lash \& Associates.

Sohlberg, M. M., \& Mateer, C. (2001). Cognitive rehabilitation. New York: Guilford. Spielberger, C., Gorsuch, R., Lushene, R., Vagg, P. R., \& Jacobs, G. A. (1983). State-Trait Anxiety Inventory: Test Manual. Palo Alto, CA: Consulting Psychologists. 
Stanley, M. A., Beck, J. G., Novy, D. M., Averill, P. M., Swann, A. C., Diefenbach, G. J., \& Hopko, D. (2003). Cognitive behavioral treatment of late-life generalized anxiety disorder. Journal of Consultng and Clinical Psychology, 71, 309-319.

Stewart, R., \& Liolitsa, D. (1998). Type 2 diabetes mellitus, cognitive impairment, and dementia. Diabetes Medicine, 16, 93-112.

Storandt, M.A. (1983). Psychology's response to the graying of America. American Psychologist, 38, 323-326.

Trenerry, M. R., Crosson, B., DeBoe, J., \& Leber, W. R. (1989). Stroop Neuropsychological Screening Test manual. Odessa, FL: Psychological Assessment Resources, Inc.

Unutzer, J., Katon, W., Sullivan, M., \& Miranda, J. (1999). Treatment of depressed older adults in primary care: Narrowing the gap between efficacy and effectiveness. Midbank Quarterly, 77, 225-256.

Waldstein, S. R., Brown, J. R., Maier, K. J., \& Katzel, L. I. (2005). Diagnosis of hypertension and high blood pressure levels negatively affect cognitive function in older adults. Annals of Behavioral Medicine, 29(3), 174-180.

Wei, T.-M., \& Wang, L. (2006). Anxiety symptoms in patients with hypertension: A communitybased study. International Journal of Psychiatry in Medicine, 36(3), 315-322.

Wetherell, J. L., Gatz, M., \& Craske, M. G. (2003). Treatment of generalized anxiety disorder in older adults. Journal of Consulting and Clinical Psychology, 71, 31-40.

White, H., Aidala, A., \& Zablocki, B. (1998). A longitudinal investigation of drug use and work patterns among middle class white adults. Journal of Applied Behavioral Science, 24, 455-469.

White Lumpkin, P., Silverman, W.K., Weems, C.F., Markham, M.R., \& Kurtines, W.M. (2002) Treating a heterogeneous set of anxiety disorders in youth with group cognitive behavioral therapy: A partially nonconcurrent multiple-baseline evalution. Behavior Therapy, 33, 163-177.

Willis, S. L., \& Schaie, K. W. (1986). Training the elderly on the ability factors of spatial orientation and inductive reasoning. Psychology and Aging, 1, 239-247. 
Table 1. Geoffrey's Pre- and Post-Treatment Scores on Self-Report Questionnaires

\begin{tabular}{|c|c|c|c|}
\hline $\begin{array}{c}\text { Pre- } \\
\text { Treatment }\end{array}$ & $\begin{array}{l}\text { Post- } \\
\text { Treatment }\end{array}$ & $\begin{array}{l}\text { \% Change } \\
\text { in Means }\end{array}$ & $\begin{array}{l}\text { Normal Mean } \\
\text { (Standard Deviation) }\end{array}$ \\
\hline
\end{tabular}

Beck Depression Inventory (BDI)

Geriatric Suicidal Ideation Scale

39

$14^{\mathrm{C}}$

$64 \%$

$5.74(6.70)$

(GSIS)

Social Anxiety Interaction Scale

89

44

$51 \%$

$39.63(12.67)$

(SAIS)

Beck Anxiety Inventory (BAI)

31

6

$81 \%$

State Trait Anxiety Inventory -

50

35

$30 \%$

$28.61(5.67)$

Trait (STAI)

Note. Normal means were derived from a sample of 30 older adults (mean age $=69.03$ ) who were free of current and past psychiatric disorders collected by the first author.

a Total time from pre- to post-treatment was ten weeks, with a total of 14 sessions, 10 of CBT/APT and 4 of exposure practice. These data were collected after session 14.

b In the “severe” range of functioning (Beck \& Steer, 1987).

c In the “mild” range of functioning (Beck \& Steer, 1987).

${ }^{\mathrm{d}}$ SAIS data from older samples is not currently available. Therefore the mean and standard deviation displayed here are from a sample of nonanxious younger adults (Mattick \& Clarke, 1998). 


\section{Table 2. Geoffrey's Pre-treatment to Post-treatment Changes on Six Neuropsychological Tests With Age- and Education-Normed Descriptive Labels of Functioning}

\begin{tabular}{llll} 
Test & Skill Measured & Pre-treatment & Post-treatment \\
\hline Digit Span & Short term memory & 47 (average) & 53 (average) \\
Verbal Paired Associates & Associative memory & 38 (low average) & 48 (average) \\
Stroop Color Trial & Sustained attention & 50 (average) & 54 (average) \\
Stroop Color-Word Trial & Inhibitory control & 32 (borderline) & 44 (average) \\
COWAT (FAS) ${ }^{\text {b }}$ & Verbal fluency & 33 (borderline) & 48 (average) \\
Similarities & Concept formation & 42 (low average) & 55 (average)
\end{tabular}

${ }^{\mathrm{a}}$ Total time from pre- to post-treatment was ten weeks, with a total of 14 sessions. These data were collected after session 14. Skill summaries from Lezak, Howieson, \& Long, 2004.

${ }^{\mathrm{b}}$ COWAT = Controlled Oral Word Association Test using stimuli F, A, and S. 
Table 3. Multiaxial, DSM Diagnoses (American Psychiatric Association, 2000) Collected at Baseline, After Session 14, and After the Six Month Follow-Up Period

Pre-treatment

Axis I: $\quad 296.30$ Major Depressive Disorder, Recurrent

300.29 Specific Phobia, Situational Type (Claustrophobia; Severe)

300.23 Social Anxiety Disorder (Generalized; Moderate)

309.81 Posttraumatic Stress Disorder (Subsyndromal)

304.80 Substance dependence (Sustained Full Remission)

Axis II:

Deferred

Axis III:

Type II diabetes

Axis IV:

Lack of resources: social support, financial

Axis V:

GAF/SOFA: 65

Post-treatment (ten weeks later)

Axis I: $\quad 300.29$ Specific Phobia, Situational Type (Claustrophobia; Mild)

309.81 Posttraumatic Stress Disorder (Subsyndromal)

304.80 Substance Dependence (Sustained Full Remission)

Axis II:

Deferred

Axis III:

Type II diabetes

Axis IV:

Axis V:

Lack of resources: social support, financial

80

$\underline{\text { Six-Month Follow Up (SCID interview administered over the phone) }}$

Axis I: $\quad 309.81 \quad$ Posttraumatic Stress Disorder (Subsyndromal)

Axis II:

304.80 Substance Dependence (Sustained Full Remission)

Axis III:

Deferred

Axis IV:

Type II diabetes, well controlled

Axis V:

Lack of resources: social support, financial

90 
Figure 1. Therapy Process Measures on the Stroop Color-Word Trial (Stroop CW) and the Beck Depression Inventory (BDI) Over Ten Weeks of Treatment

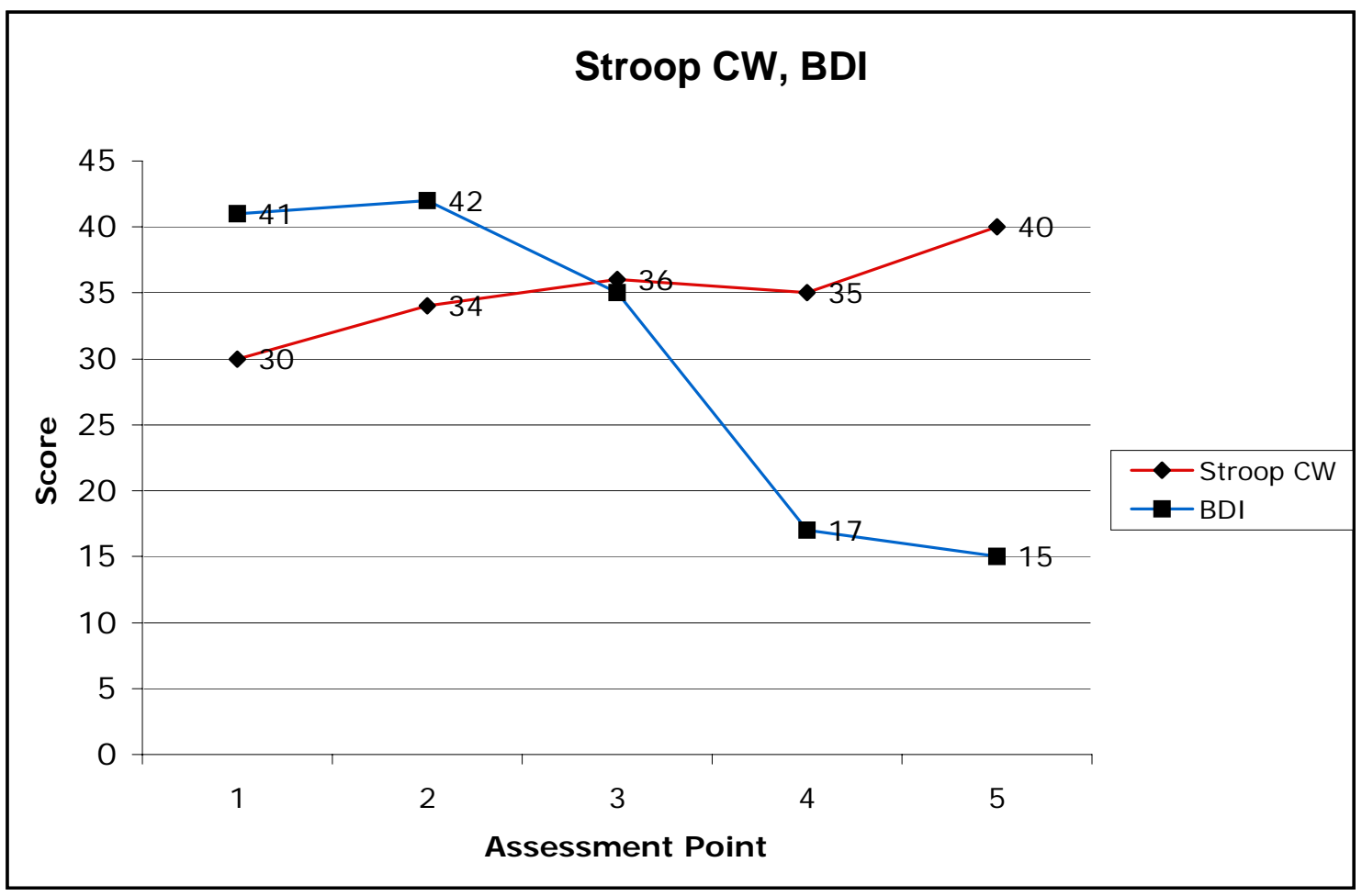

Note. Each score is collapsed over multiple therapy sessions and rounded off to the nearest whole number. Total time in treatment (assessment points 1-5) was nine weeks, across 10 sessions of CBT/APT. No data were collected during the final week of treatment, which consisted of exposure practice. Assessment Point 1 = average scores from weeks 1-2 (3 sessions); Assessment Point 2 = average scores from weeks 3-4 (2 sessions); Assessment Point 3 = average scores from weeks 5-6 (2 sessions); Assessment Point 4 = average scores from weeks 7-8 (2 sessions); Assessment Point 5 = average scores from weeks 9-10 (2 sessions). Stroop CW scores are T-scores; BDI scores are raw scores. 
Figure 2. Daily Mood Ratings Made on a "0" To "8” Likert-Type Scale for Sessions 1-10

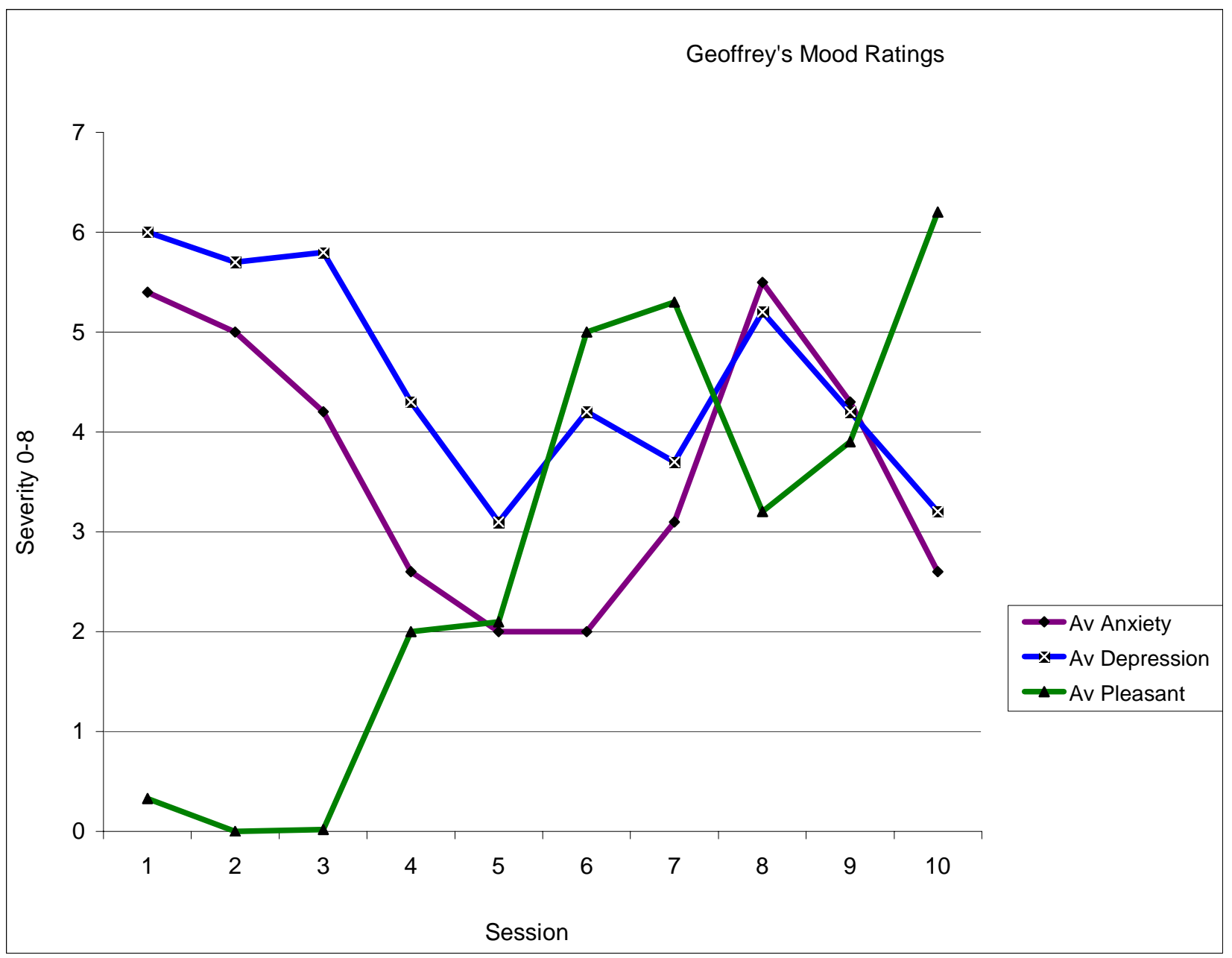

Note. Scores reflect the average rating made on the mood record that was assigned as homework in each of the sessions shown above. Due to the schedule of therapy sessions, the scores for sessions 1- 4 were averaged over three or four day periods, whereas all subsequent scores were averaged over one-week periods. Data were collected over nine-weeks, with the last set of ratings collected in session 10. Mood rating data were not collected during the final week of treatment, which consisted of exposure practice. 